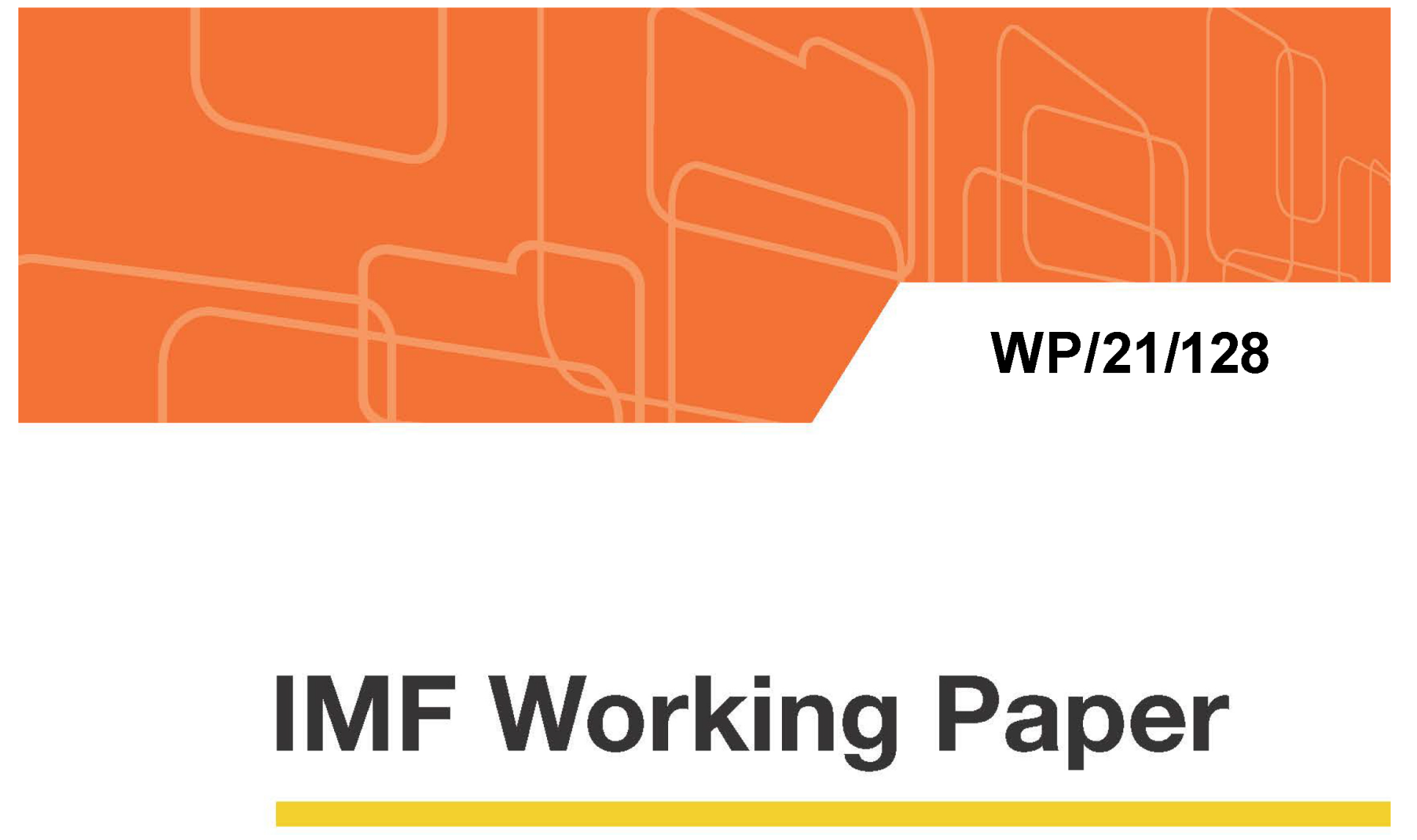

\title{
The Cost of Future Policy: Intertemporal Public Sector Balance Sheets in the G7
}

by Yugo Koshima, Jason Harris, Alexander F. Tieman, and Alessandro De Sanctis

IMF Working Papers describe research in progress by the author(s) and are published to elicit comments and to encourage debate. The views expressed in IMF Working Papers are those of the author(s) and do not necessarily represent the views of the IMF, its Executive Board, or IMF management. 


\title{
IMF Working Paper
}

Fiscal Affairs Department

\section{The Cost of Future Policy: Intertemporal Public Sector Balance Sheets in the G7 \\ Prepared by Yugo Koshima, Jason Harris, Alexander F. Tieman, and Alessandro De Sanctis ${ }^{1}$}

Authorized for distribution by Carolina Renteria

May 2021

\begin{abstract}
IMF Working Papers describe research in progress by the author(s) and are published to elicit comments and to encourage debate. The views expressed in IMF Working Papers are those of the author(s) and do not necessarily represent the views of the IMF, its Executive Board, or IMF management.
\end{abstract}

\begin{abstract}
This paper compiles the Intertemporal Public Sector Balance Sheets for all G7 countries and examines their relationship with government borrowing costs. In 2018, all G7 countries have negative Intertemporal Net Financial Worth (INFW), falling short of their intertemporal budget constraint. A decomposition of the evolution of INFW shows that short-term fluctuations are mainly driven by fiscal policy changes, while in the long run demographic changes and health and pension obligations play a larger role. We find that on average a 10 percentage point of GDP increase in INFW reduces the (future) 10-1 year sovereign yield curve spread by 2.8 basis points. This results suggest that financial markets pay attention to governments' future policy obligations, in addition to its current assets and liabilities.

JEL Classification Numbers: H50, H60, H63, E62, J11

Keywords: Public Sector Balance Sheet; G7; Canada; France; Germany; Italy; Japan; UK; US; Fiscal Sustainability; Intertemporal Net Financial Worth.

Author's E-Mail Address: ykoshima@,imf.org; jharris@,imf.org; atieman@imf.org; aledesanctis@hotmail.it
\end{abstract}

\footnotetext{
${ }^{1}$ We a re grateful for helpful comments and suggestions from Bas Bakker, Nigel Cha lk, PaulCashin, Ruo Chen, Ernesto Crivelli, Mark Fla nagan, Fa bien Gonguet, Nikolay Gueorgu iev, Bertrand Gruss, Alejandro Hajdenberg, Takuma Hisanaga, James Daniel, Troy Matheson, Mariano Moszoro, Aiko Mineshima, Cathy Pattillo, Gemma Preston, John Ralyea, Ranil Sa lgado, Anita Tuladhar, and Qia nqian Zhang. Reza Yousefi provided excellent discussions and analysis from which this paper benefitted.
} 
Table of Contents

ABSTRACT_____________________________________________________

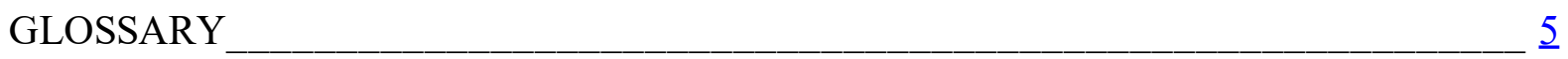

I. INTRODUCTION___________________________________________________

II. INTERTEMPORAL PUBLIC SECTOR BALANCE SHEET FRAMEWORK_______ $\underline{8}$

III. ESTIMATING INTERTEMPORAL NET (FINANCIAL) WORTH ____ 12

IV. EVOLUTION OF G7'S INTERTEMPORAL PUBLIC SECTOR BALANCE SHEET 20

V. INFW AND BORROWING COSTS _______

VI. CONCLUSIONS ______ $\underline{30}$

FIGURES

1. The Balance Sheet Framework $\underline{6}$

2. Annual Growth Rate of Per Person Health Spending, 2000-17

3. Baseline Discount Rate Assumptions

4. Interest-Growth Differentials of Baseline Assumptions

5. Public Sector Balance Sheet, 2016

6. Net Financial Worth of Public Sector

7. Changes in Net Financial Worth, 2016-18

8. Intertemporal Net Financial Worth, 2018

9. Baseline Projections of Primary Balances

10. Baseline Projections of Health Expenditure

11. Projections of Health Expenditure

12. Baseline Projections of Pension Expenditure

13. Size of Adjustments to Make INFW 0

14. Baseline Projections of Real GDP Growth

15. INFW

16. Alternative Scenario of Interest-Growth Differentials

17. INFW under Two Scenarios of Interest Paths (Percent of GDP)

18. INFW

19. Intertemporal Net Worth, 2018

20. INW under Three Scenarios of Capital Expenditure

21. Size of Adjustments to Make INW 0

22. Canada: Intertemporal Net Financial Worth

23. Canada: Decomposition of Changes in INFW

24. Japan: Intertemporal Net Financial Worth

25. Japan: Decomposition of Changes in INFW

26. UK: Intertemporal Net Financial Worth

27. UK: Decomposition of Changes in INFW

28. Cumulative Changes in INFW 1989-2018 
29. Durations of INFW

\section{TABLES}

1. Panel Estimates: Dependent Variable) $\underline{28}$

2. Fixed Effects and Country Specific Estimates: Dependent Variable

3. Unit Root Tests (P-Value)

\section{APPENDICES}

I. Methods for Updating Net Financial Worth

II. Underlying Assumptions for Baseline Case

III. Sensitivity of INFW to Interest Rate Changes

IV. Methods for Estimating Intertemporal Net Worth

\section{REFERENCES}

References 


\section{GLOSSARY}

$\begin{array}{ll}\text { CBO } & \text { Congressional Budget Office of the US } \\ \text { OBR } & \text { Office for Budget Responsibility of the UK } \\ \text { CR } & \text { Coverage Ratio } \\ \text { GFSM } & \text { Government Finance Statistics Manual } \\ \text { IMF } & \text { International Monetary Fund } \\ \text { INFW } & \text { Intertemporal Net Financial Worth } \\ \text { INW } & \text { Intertemporal Net Worth } \\ \text { IPSBS } & \text { Intertemporal Public Sector Balance Sheet } \\ \text { NFW } & \text { Net Financial Worth } \\ \text { NW } & \text { Net Worth } \\ \text { OADR } & \text { Old Age Dependency Ratio } \\ \text { PSBS } & \text { Public Sector Balance Sheet } \\ \text { RR } & \text { Replacement Ratio } \\ \text { WEO } & \text { World Economic Outlook }\end{array}$




\section{INTRODUCTION}

1. Public Sector Balance Sheets (PSBS) present all of the accumulated assets and liabilities under the control of government. The assets and liabilities in the PSBS include not only the central, state and local governments, but also extrabudgetary units, public corporations, natural resources and pension liabilities to public sector employees. As such the PSBS framework goes beyond the standard fiscal view of debts and deficit by bringing a focus on assets and enlarging coverage to the entire public sector (Figure 1). Therefore, the PSBS provides a comprehensive view of public wealth.

Figure 1. The Balance Sheet Framework

The public sector balance sheet ex tends coverage to public corporation and includes future revenues and spending

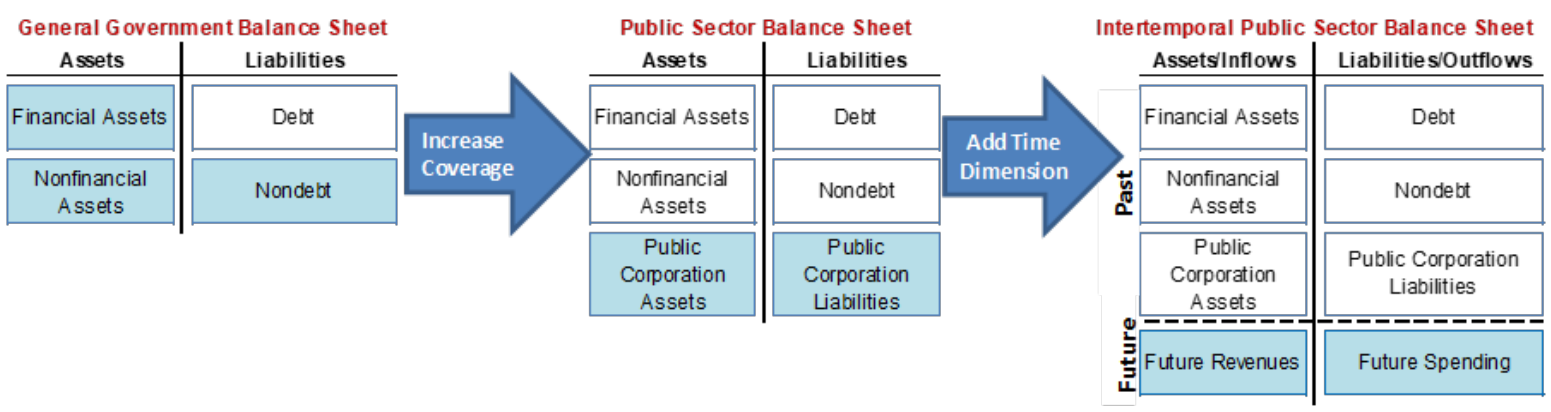

Source: October 2018 Fiscal Monitor

Note: Blue boxes denote incremental additions to the framework

2. The intertemporal PSBS (IPSBS) goes further still, by combining the static balance sheet with the costs of future fiscal policy. It does so by calculating the net present value of future expenditure and revenue and combining these number with liabilities and assets in the static PSBS. The IPSBS thus presents a complete picture of long-term fiscal health, measured against the intertemporal budget constraint all governments face. It allows for the analysis of different future fiscal policies and assessment of whether such policies improve or worsen long-term fiscal health.

3. While using balance sheet analysis to assess fiscal policies is not new, it has gained renewed impetus over the last few years. The concept started in the 1930s with the publication of the central government balance sheet in Weimar Germany (Finanzministerium 1933), followed by a questionnaire on government balance sheets from the League of Nations (1938). Over the last few decades, government balance sheets have been used in fiscal analysis by, among others, Buiter (1983), Allen and others (2002), and Traa and Carare (2007). Individual asset categories in the balance sheet have also been analyzed in depth, e.g., natural resources in IMF (2012), nonfinancial assets in Bova and others (2013), and financial asset returns in Seiferling and Tareq (2015), while stock-flow adjustments are discussed in Jaramillo and others (2017).

4. More recently, the October 2018 Fiscal Monitor (IMF 2018) compiled the PSBS for countries worldwide. It looked at a sample of 31 countries encompassing advanced 
economies, emerging markets and low-income countries. The accompanying database (IMF, 2019) has since been enlarged to now cover 38 countries comprising some two-thirds of global GDP. The Monitor and accompanying papers showed how balance sheet analysis can be used for fiscal risk assessment and management (Gonguet and Hellwig, 2019). Crucially, it highlighted the role of public assets, documenting how these assets (that contribute directly balance sheet strength) matter, as countries with stronger public sector balance sheet positions on average face shallower and shorter recession and pay lower interest rates on their borrowing (Yousefi, 2019). The Monitor also discussed the intertemporal balance sheet as a tool for policymakers to assess options for future fiscal policy, and provided illustrations of such an approach for Finland (Brede and Henn, 2018 and 2019), Norway (Cabezon and Henn, 2018 and 2019), and Indonesia (E1 Rayess et. al., 2019).

\section{This paper applies the concept of the intertemporal balance sheet to the $\mathbf{G} 7$} countries, covering the period before the COVID-19 pandemic. ${ }^{2}$ It lays out the framework for IPSBS analysis in detail. It then assesses the strength of the public sector in each of the G7 countries, on currently implemented and legislated policies as of the end 2018. It presents findings both in terms of intertemporal net financial wealth (INFW) and a hypothetical one-time fiscal adjustment that would balance countries' books. It also provides comprehensive sensitivity analysis on these findings. Lastly, it documents the evolution of INFW over time for the three G7 countries where data are available, and decomposes INFW changes into its main components, showing the importance of both demographic developments and fiscal policy changes. In particular, modest but sustained fiscal consolidation is shown to have very significant effects on INFW.

\section{The paper examines the relationship between long-term interest rates on sovereign borrowing and the strength of a country's intertemporal balance sheet.} Regressions of slopes of future yield curves on INFW for Canada, the UK and Japan find a modest but statistically significant relationship. On average, a 10-percentage point of GDP increase in INFW reduces spreads between the ten-year ahead one- and ten-year interest rates on government bonds by 2.8 basis points. This suggests that when INFW improves, the yield curve flattens, possibly as market participants reassess their views on sovereign credit and interest rate risks. While challenges remain in the robustness of estimation given the limited sample size, this result suggest a possibility that financial markets take account of governments' long-term obligations and future revenue potential. As such, it may belie the widely held perception that as promises of future health and pension spending are not traded on financial markets, no market signals exist with respect to the likelihood that government are able to meet these future obligations (The Economist, 2020 and Munnell et. al., 2011).

7. The remainder of this paper is organized as follows. The next section presents a detailed framework for intertemporal balance sheet analysis. Section III discusses the baseline projections of INFW for the G7 countries and presents sensitivity analysis around

\footnotetext{
${ }^{2}$ We intend to analyze the effects of the COVID-19 pandemic on IPSBS strength in future work.
} 
these projections. Section IV examines the evolution of the G7's INFW over time, while Section V uses these dynamics to examine the relationship between INFW and interest rates on long-term sovereign borrowing. Finally, Section VI concludes.

\section{Intertemporal Public Sector Balance Sheet Framework}

\section{Expanded Intertemporal Budget Constraint Model}

8. In many studies, analysis of fiscal sustainability begins with the intertemporal budget constraint model. ${ }^{3}$ In this model, the accounting identity of changes in government debt stock $\left(B_{t}-B_{t-1}\right)$ is expressed as the difference between primary expenditure $\left(G_{t}\right)$ and revenue $\left(R_{t}\right)$ plus interest payments $\left(r_{t} B_{t-1}\right)$ :

$$
B_{t}-B_{t-1}=G_{t}-R_{t}+r_{t} B_{t-1}
$$

This can be expressed in percent of nominal GDP $\left(Y_{t}\right)$ and its annual growth rate $\left(g_{t}\right)$ as follows:

$$
\frac{B_{t}}{Y_{t}}-\frac{B_{t-1}}{Y_{t-1}}=\frac{G_{t}-R_{t}}{Y_{t}}+\frac{1+r_{t}}{1+g_{t}} \frac{B_{t-1}}{Y_{t-1}}
$$

When we solve this forward, the intertemporal budget constraint is:

$$
\frac{B_{t}}{Y_{t}}=\sum_{j=1}^{\infty} d_{j} \frac{R_{t+j}-G_{t+j}}{Y_{t+j}}+\lim _{T \rightarrow \infty} \prod_{j=1}^{T} d_{T} \frac{B_{T}}{Y_{T}}
$$

where the discount factor is $\mathrm{d}_{j}=\prod_{k=1}^{j} \frac{1+g_{t+k}}{1+r_{t+k}}$

In order to avoid a situation where an individual would have to hold government bonds at some infinite point in the future, it is commonly assumed that in the very long run all debt should be repaid, i.e., $\lim _{T \rightarrow \infty} \prod_{j=1}^{T} d_{T} \frac{B_{T}}{Y_{Y}}=0$. The following equation derived from this process highlights the well-known concept that the debt stock is equal to the net present value of future primary balances:

$$
\frac{B_{t}}{Y_{t}}=\sum_{j=1}^{\infty} d_{j} \frac{R_{t+j}-G_{t+j}}{Y_{t+j}}
$$

9. The October 2018 Fiscal Monitor (IMF 2018) expands the intertemporal budget constraint model by using INFW, which captures public sector nondebt liabilities and financial assets in addition to debt. Non-debt liabilities, such as civil servant pension liabilities, represent important future obligations of the government. Financial assets are relatively liquid, and also have implications for the government's ability to meet its obligations. ${ }^{4}$ Nonfinancial public assets are not taken into account when calculating INFW.

\footnotetext{
${ }^{3}$ For exa mple, see Chalk and Hemming (2000), Crowder(1997), Gia mmarioli et. al. (2007), Debrun et. al. (2018).

${ }^{4}$ Gia mmarioli et. al. (2007) high lights these shortcomings.
} 
These assets are hard to value, as they typically do not have market valuations and may not generate cash flow. In contrast, valuation is more reliable for financial assets, for which some information on markets value or cashflow is usually available. In the INFW concept, both assets and liabilities are defined at the level of the entire public sector, which comprises all government-controlled financial and nonfinancial public corporations, in addition to the general government. ${ }^{5}$

10. INFW combines static NFW with the future costs of fiscal policy. It is defined as:

$$
I N F W_{t}=N F W_{t}+\sum_{j=1}^{T} \frac{R_{t+j}-G_{t+j}}{(1+r)^{j}}
$$

where $N F W_{t}=F A_{t}-L_{t}\left(F A_{t}\right.$ : financial assets, $L_{t}$ : total liabilities $)$.

The first element in this equation is static NFW of the public sector, which represents consequences of past fiscal policy. As in the intertemporal budget constraint model, the second element in this equation uses the present values of general government primary balances, net of interest payments, to show the future costs of fiscal policy. This element does not include present values of public corporations' profits, which are largely captured already in the static balance sheet as equity. The solvency condition under this model requires INFW to be at least zero under normal conditions for growth and interests. Unlike the intertemporal budget constraint based on the concept of debt alone, under the INFW model the solvency condition can be satisfied even when the present values of primary deficits exceed those of primary surpluses, as long as the government has a corresponding positive NFW.

\section{Methods}

\section{Static NFW is computed by following the methodologies of the IMF PSBS} database. As described in IMF (2018) and further detailed in Alves et. al. (2020), the IMF PSBS database covers the entire consolidated public sector including both general government and public corporations, currently up to the year 2016. This paper updates NFW for the G7 countries up to 2018 by following the same data sources and methodologies. Appendix I presents methods for updating NFW.

\section{The future costs of fiscal policy are computed by making long-term fiscal} projections for 50 years on an assumption of unchanged policy. As mentioned in the OBR (2011), fiscal policies for the medium-term are usually publicly announced and welldefined, while a long-term policy is not clearly defined. Although it is unrealistic to assume that the government maintains the same policy over the very long-term, as mentioned in the CBO (2019), the unchanged policy assumption provides a point of comparison from which to measure adjustment needs and the impact of policy changes.

\footnotetext{
${ }^{5}$ Crossholdings within thepublic sector a re consolidated.
} 


\section{Our baseline long-term projections focus on the impact of population aging, by} holding other factors constant. The projections follow the methodologies of IMF (2018) and Amaglobeli and Shi (2016). For the medium-term (Year 1 to 6), we take the macro-fiscal projections from the October 2018 IMF World Economic Outlook (WEO) database. For the long-term (Year 7 to 50), output projections use a simple production function approach expressed by the following equation:

$$
g_{t}^{Y}=\beta\left(g_{t}^{L}+g_{t}^{H W}\right)+(1-\beta) g_{t}^{K}+g_{t}^{T F P}
$$

where $g_{t}{ }^{Y}$ is the real growth rate of GDP, $g_{t}{ }^{L}$ is a growth rate of workers, $g_{t}{ }^{H W}$ is a growth rate of hours worked, $g_{t}{ }^{K}$ is a growth rate of capital stock, $g_{t}^{T F P}$ is a growth rate of total factor productivity, and $\beta$ is a labor share in outputs. Population projections are derived from the 2017 UN World Population Prospects (UN Population Division, 2017). We compute $g_{t}{ }^{L}$ by multiplying future population projections by the employment rate for each age cohort, which is assumed to remain constant at its Year 0 level. $\beta$ is held constant at the level of 5-year historical average. To smoothen a transition from WEO to long-terms projections, $g_{t}{ }^{H W}$ is computed as a difference between WEO's projection of employment growth and $g_{t}{ }^{L}$ calculated above for Year 6 and held constant at that level. Similarly, $g_{t}{ }^{K}$ is held constant at the level of WEO's projection of real gross fixed capital formation growth for Year 6; and $g_{t}^{T F P}$ is also held constant at the Year 6 rate calculated as residuals between real growth and other variables in the WEO projections. Fiscal projections assume that primary revenue and expenditure other than health and pension expenditure remain constant as share of GDP at the Year 6 level projected in the WEO database ${ }^{6}$ Therefore, projections of primary balances are driven by developments of health and pension expenditure, which will have the greatest impact on public finance in the long run given population aging.

\section{Pension expenditure is influenced by changes in demography and key policy} parameters. ${ }^{7}$ Projections of pension expenditure are based on the following equation:

$$
P E_{t}=\text { Pop }_{t}^{65+} \times C R_{t} \times \frac{G D P_{t}}{\text { Workers }_{t}} \times R R_{t}
$$

where $P E_{t}$ is old-age pension expenditure, $P o p_{t}^{65+}$ is population above 65 years old, $C R_{t}$ is a coverage ratio defined as a share of pensioners in population above 65 years old, $R R_{t}$ is a replacement rate defined as a ratio of per-person pension to per-worker GDP. In this model, $C R_{t}$ and $R R_{t}$ are determined by the government policy. The coverage ratio captures the retirement age, while the replacement ratio shows the generosity of pension benefits relative to wages. Assumptions on $C R_{t}$ and $R R_{t}$ incorporate announced and codified policy, including policy to be implemented in the future. In order to avoid double counting, pension expenditure does not include public service pensions, the liabilities of which are already

\footnotetext{
${ }^{6}$ This a pproach is suggested in, e.g., the International Federation of Accountants (2011)

${ }^{7}$ Pension expenditure focuses on old-age pensions and does not include other types of pensions such as disability pensions.
} 
included in the static NFW.

\section{Health expenditure is driven by growth of per capita health spending,} which is faster than economic growth. In all seven countries, per capita health expenditure (including long-term care) has been growing faster than per capita GDP for the last two decades (Figure 2). While few statistics are available to decompose this growth, the increase in per-person health spending appears to be driven by both price and volume increases, depending on the health policy. ${ }^{8}$ To capture these growth effects, projections of health expenditure are based on the following equation:

Figure 2. Annual Growth Rate of Per Person Health Spending, 2000-17 (Percent)

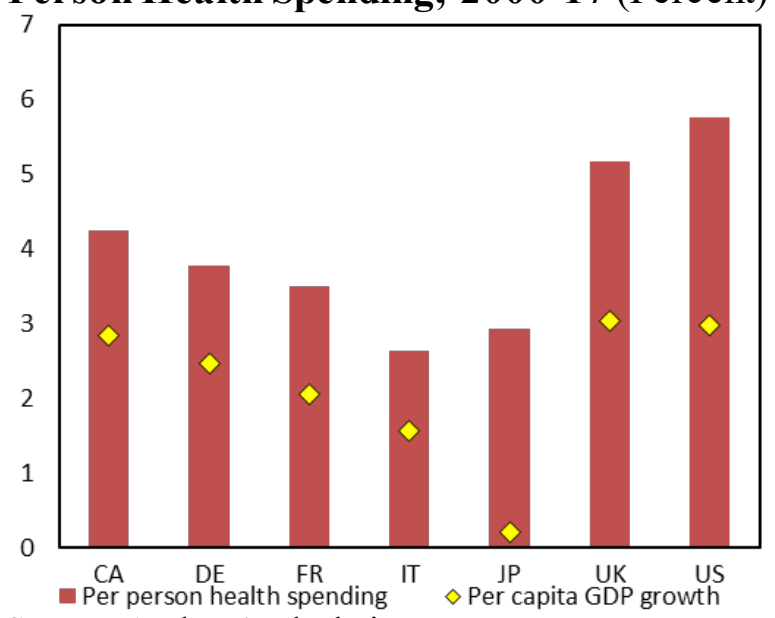

Source: Authors' calculations

$H E_{t}=P o p_{t}^{65+} \times \frac{H E_{t-1}^{65+}}{P o p_{t-1}^{65+}} \times\left(1+\alpha^{65+} \times g_{t}^{G D P P C}\right)+P o p_{t}^{0-64} \times \frac{H E_{t-1}^{0-64}}{P o p_{t-1}^{0-64}} \times\left(1+\alpha^{0-64} \times g_{t}^{G D P P C}\right)$

where $H E_{t}$ is total health expenditure, $H E_{t}{ }^{65+}$ and $H E_{t}{ }^{0-64}$ are respectively health expenditure for the population above 65 years old and below 64 years old, $g_{t} G D P P C$ is the growth rate of GDP per capita, and $\alpha$ is an acceleration factor that captures growth of health spending relative to growth of GDP (both in per capita terms). The baseline value of $\alpha$ is derived from historic averages and applied throughout the projection horizon.

\section{We apply the same discount rates to all seven countries in our baseline. This}

intends to eliminate from the INFW estimation the effects of difference in discount rates, to which the INFW is sensitive (as discussed in more detail below). However, this means that interest-growth differentials are different across countries. ${ }^{9}$ In the baseline, discount rates use the average interest projections for seven countries in the October 2018 WEO for the medium term. For the long-term, interest rates are assumed to increase gradually until 2049 to reach $4 \frac{1}{2}$ percent, - the average of long-run interest projections made by other institutions. ${ }^{10}$ It is

\footnotetext{
${ }^{8}$ In Japan, for example, the volume of services provided by the la tter-stage elderly insurance was increased by 3.5 percent in 2017, while the unit price was increased by 0.7 percent. In case of the long-term care insurance, the volume was decreased by 2.0 percent, while the unit price was increased by 4.5 percent in 2017.

${ }^{9}$ We a lso compute a nalternative measure of INFW using country-specific interest rates that a llow interestgrowth differentials to converge to the same level in the long run.

${ }^{10}$ These include the following: Canada - 4.0 percent between 2023-2091 (the Fiscal Sustainability Report 2018 by the Pa rlia mentary Budget Officer), Germany, Fra nce, Italy, and UK - 5.0 percent between 2026-2070 (the 2018 Aging Report by the European Commission), Japan - 3.0 percent in 2044(the 2014 ActuarialEstimate by the Ministry of Health, La bor and Welfare), and US - 4.6 percent in 2049 (the 2019 Long-Term Budget Outlook by the Congressional Budget Office). The weighted averages of these figures by GDPs a re 4.5 percent. The sa me figure changes little (4.4 percent) if we use the projections made a fter the COVID-19 pandemic.
} 
held constant at that level afterwards (Figure 3). Given difference in growth outlooks (discussed below), interest-growth differentials of Japan and Italy are positive for most of the projection period, while in other countries the differentials become positive only in the 2030s (Figure 4).

Figure 3. Baseline Discount Rate Assumptions (Percent)

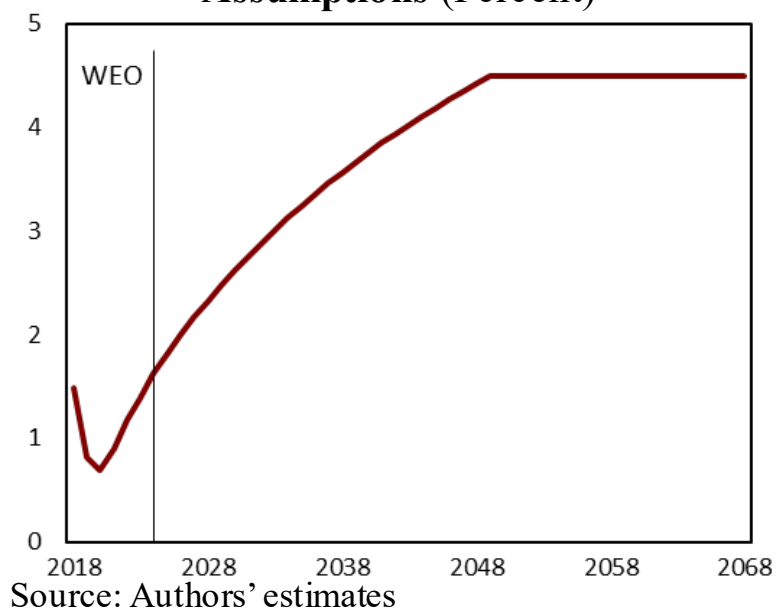

Figure 4. Interest-Growth Differentials of Baseline Assumptions (Percent)

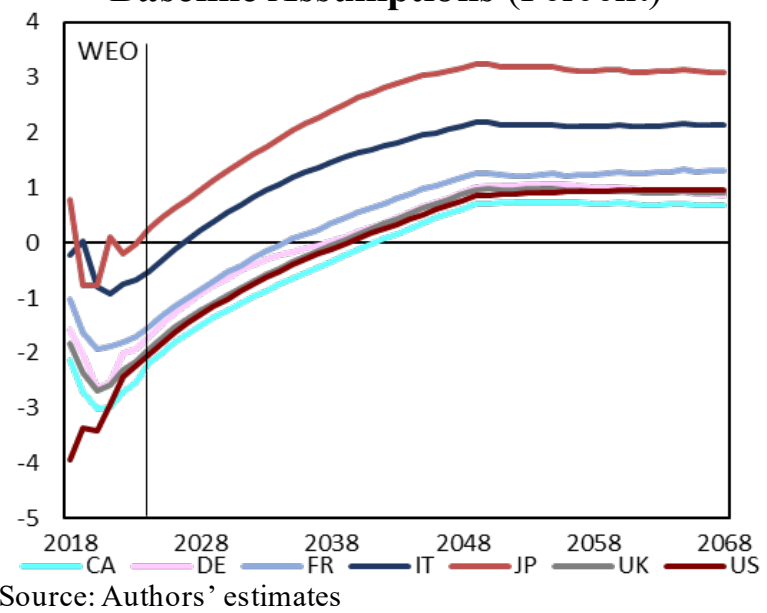

\section{ESTIMATING INTERTEMPORAL NET (FINANCIAL) WORTH}

\section{Static PSBS}

\section{The size of the PSBS varies} considerably across seven countries (Figure 5). The static PSBS of all seven countries feature large amounts of consolidated assets and liabilities, averaging 190 percent and 225 percent of GDP respectively in 2016. Out of the total average assets, some 94 percent of GDP comprise nonfinancial assets and 96 percent of GDP are financial assets. When we compare the financial assets and liabilities with the average of 31 countries $(86$ percent of GDP of financial assets and 152 percent of GDP of liabilities) presented in IMF (2018), the $\mathrm{G} 7$ countries have assets of a
Figure 5. Public Sector Balance Sheet, 2016

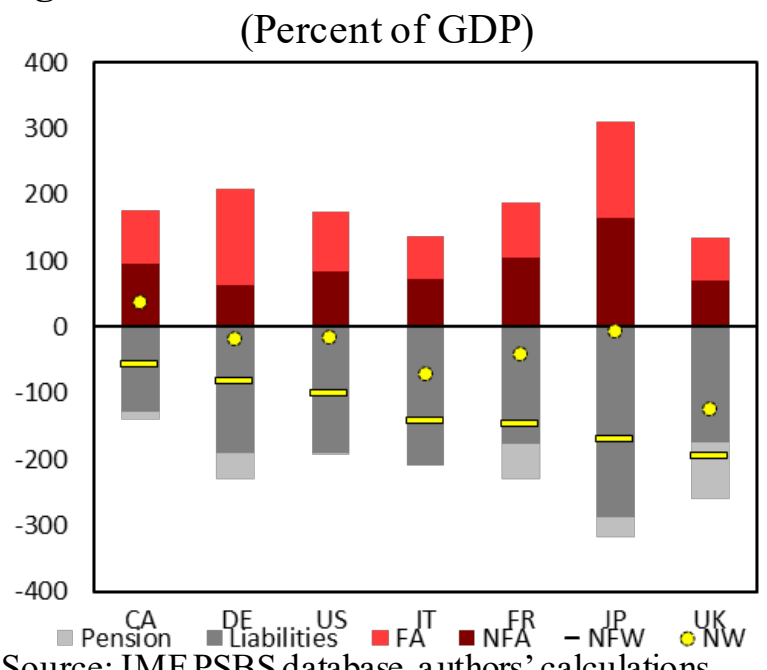

Source: IMF PSBS database, a uthors' calculations similar size but much higher liabilities. The amount of consolidated public sector liabilities ranges from 140 percent of GDP in Canada to 317 percent of GDP in Japan, with general government debt the biggest contributor. Some countries also have a large amount of public service pension obligations ( 87 percent of GDP in UK). The amount of consolidated public 
sector assets ranges from 135 percent of GDP in UK to 311 percent of GDP in Japan. On average in these seven countries around half of public sector assets comprise nonfinancial assets, mainly in the form of infrastructure owned by the general government.

18. Four out of seven countries have net worth in or close to positive territory. Canada has positive net worth (+36 percent of GDP in 2016) due mainly to large nonfinancial assets (including natural resources). This is followed by Japan, US, and Germany, whose static net worth are only slightly negative. In contrast, the UK and Italy have large static negative net worth.

19. All seven countries have large negative static NFW in 2018. This means that, assuming countries maintain their current capital stock, all seven countries on average need to run future primary surpluses in order to meet the intertemporal budget constraint based on the INFW concept. The size of NFW varies significantly across seven countries, ranging from -47 percent of GDP in Canada to -190 percent of GDP in UK in 2018 (Figure 6). This wide range indicates that levels of future primary balances needed to meet the intertemporal budget constraint differ significantly across the seven countries.

20. Changes in static NFW over time have been driven by different factors in the seven countries. In particular, Gonguet and Hellwig (2019) and Koshima (2019) document the importance of asset revaluation in net worth developments for the US and Japan. In all seven countries, static NFW has improved between 2016 and 2018 (Figure 7). Canada and Germany in particular have experienced sizable improvements in static NFW, at more than 10 percent of GDP each. In Canada the improvement stems mainly from an increase in the value of general government assets, while in Germany it is driven by a reduction in general government debt.

Figure 6. Net Financial Worth of Public

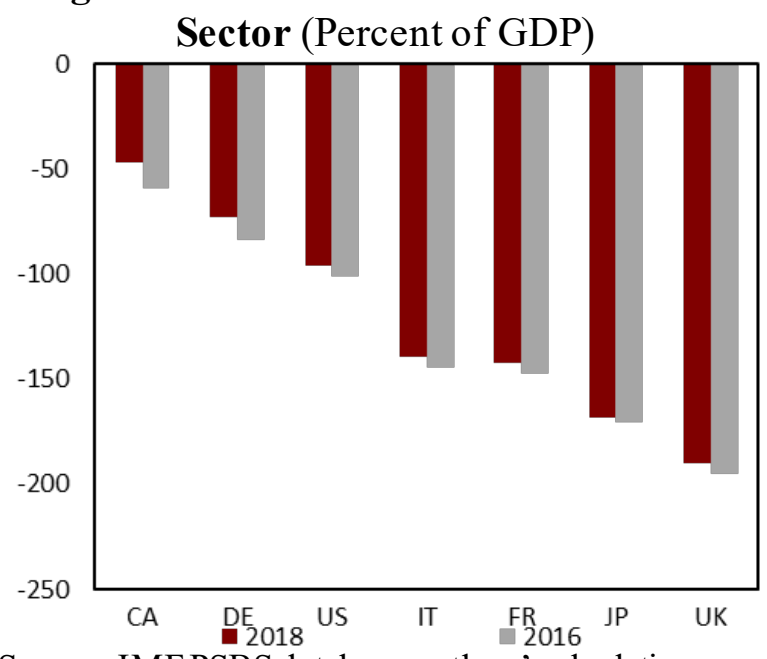

Source: IMF PSBS database, a uthors' calculations
Figure 7. Changes in Net Financial Worth,

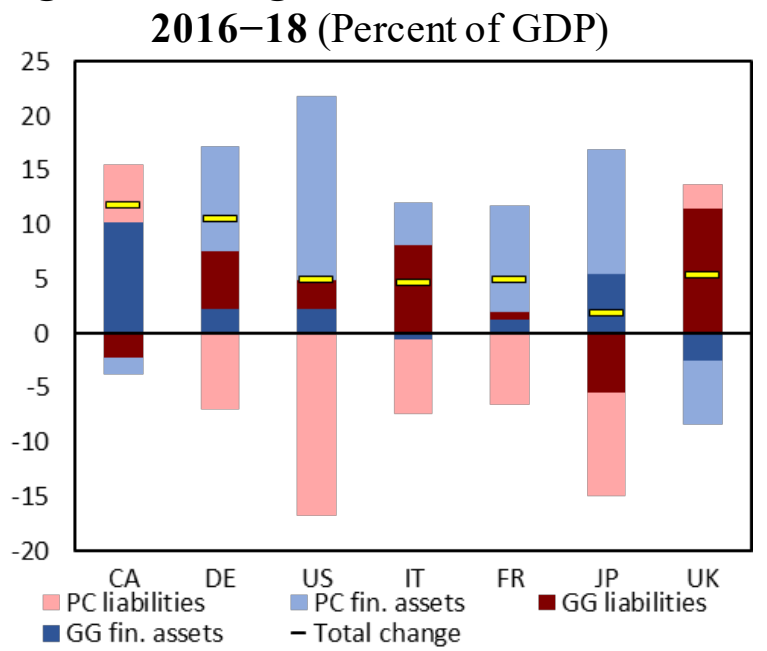

Source: Authors' calculations 


\section{Overview of Baseline Projections}

21. All G7 countries feature large negative INFW. The INFW in 2018 ranges from -170 percent of GDP in Canada to -392 percent of GDP in the US (Figure 8). On top of their negative static NFW, the costs of future policies add significantly to liabilities in all seven countries. In other words, on current policies none of seven countries will meet the intertemporal budget constraint within the 50-year horizon.

\section{Large projected future primary deficits contribute to the negative INFW in all} countries. As discussed above, the projections are produced by using the same methods for all seven countries. As shown in Appendix II, the projections for pension and health expenditure, the only drivers of long-term primary balance projections, are broadly in line with country specific projections produced by other institutions. Projected paths of primary balances somewhat vary across countries (Figure 9). In all countries except for Italy, primary deficits follow a downward trajectory throughout the projection horizon. This is due mainly to rising health spending (discussed below). The UK is projected to see the largest drop of primary balances by over 9 percentage points of GDP between 2018 and 2068, followed by Germany at just over 8 percentage points. In Italy, the primary balances are projected to gradually improve toward the end of the projection horizon, following a decrease in pension spending, due partly to demographic factors unique to Italy (discussed below). Appendix II provides details of results and assumptions of baseline macroeconomic and fiscal projections for all seven countries.

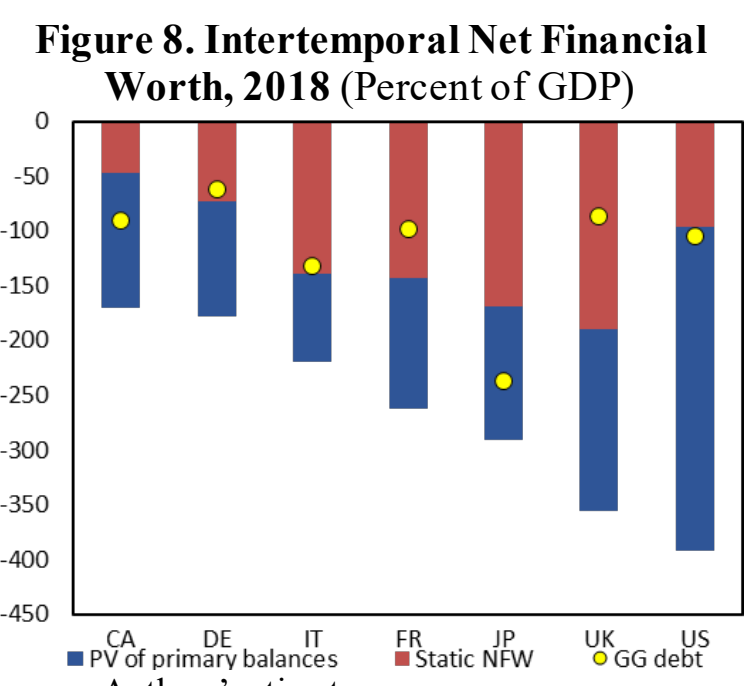

Source: Authors' estimates

Note: debt is shown in negative terms
Figure 9. Baseline Projections of Primary Balances (Percent of GDP)

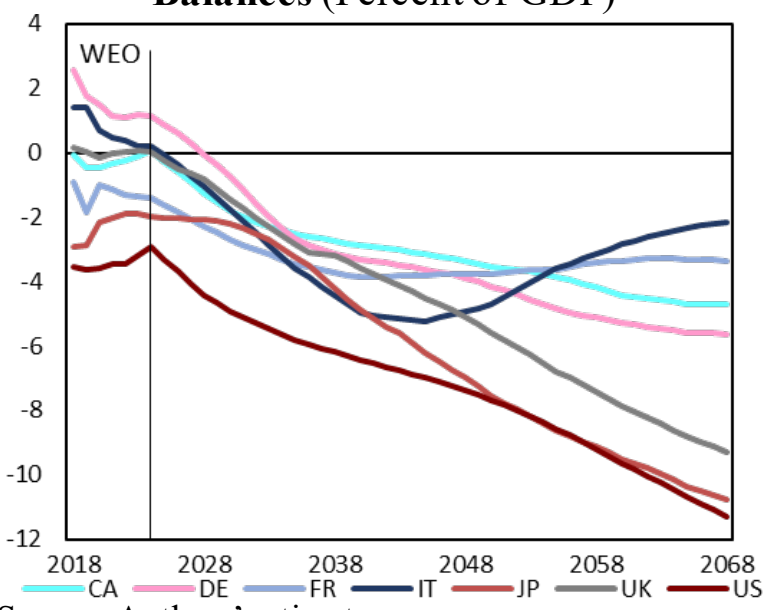

Source: Authors' estimates 
Figure 10. Baseline Projections of Health

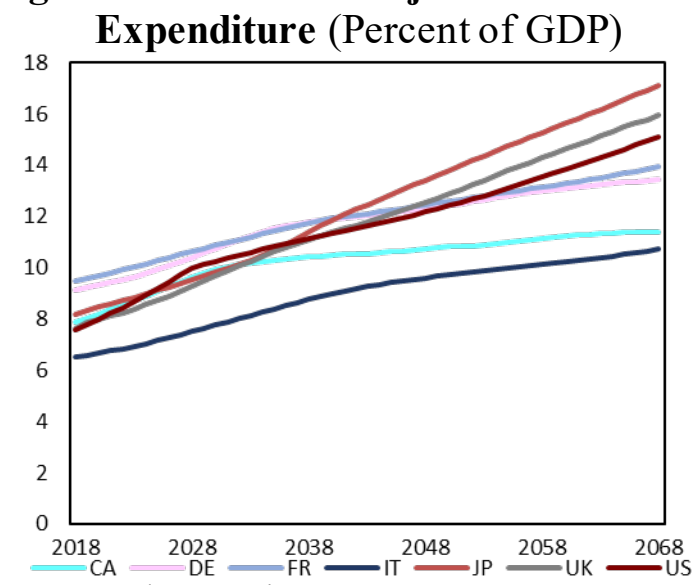

Source: Authors' estimates

\section{These projected primary deficits}

are in turn largely driven by rising health spending, while pension spending is projected to remain broadly at its current level throughout the projection horizon.

The rise of health spending is driven by fast growth of per person health spending (Figure 10). ${ }^{11}$ Japan is projected to have the largest increase in health spending by almost 9 percentage points of GDP between 2018 and 2068, followed by UK, where health spending is projected to increase by 8 percentage points over the same period. Other countries are not far behind, with the health spending projected to increase by
Figure 11. Projections of Health

Expenditure (Percent of GDP)

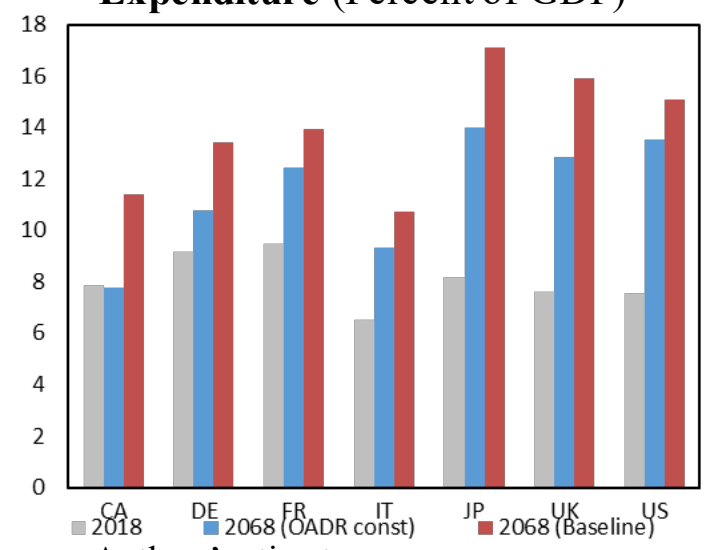

Source: Authors' estimates

Figure 12. Baseline Projections of Pension Expenditure (Percent of GDP)

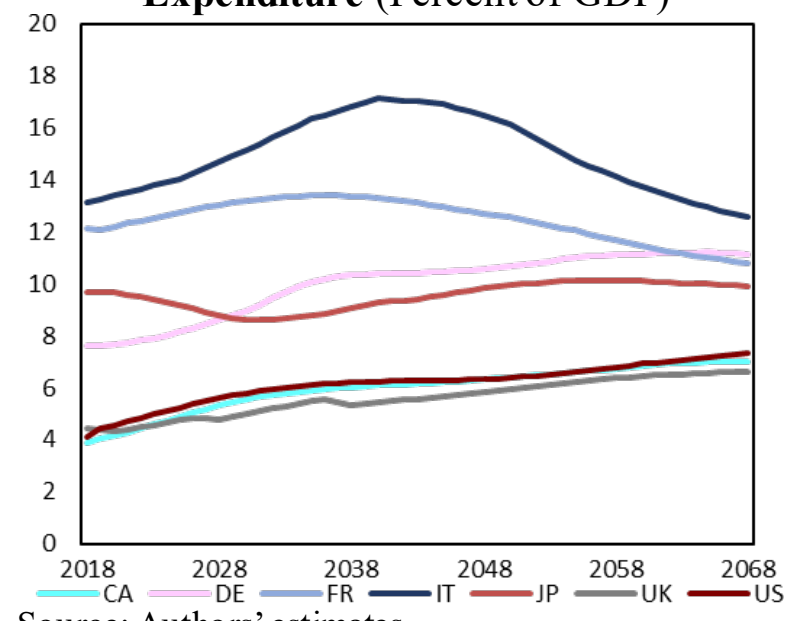

Source: Authors' estimates 3 percentage points in Canada, the lowest increase among peers. We compare these projections with those excluding the effects of aging by holing Old Age Dependency Ratios (OADR) constant at the 2018 levels (Figure 11). The results show that in Canada and Germany an increase in health expenditure is driven by population aging, while in other countries an increase in per-person health spending through price and volume increases is the main driver. In contrast, pension spending is projected to remain at its current level or increase only modestly in most countries (Figure 12). This is due mainly to the existing pension policy that counteracts pressures from population aging by increasing the retirement age and reducing the replacement rate. An exception is Italy, where pension spending is projected to drop sharply after the 2040 s, when population aging is projected to reverse.

\footnotetext{
${ }^{11}$ In the rea lgrowth projections, TFP growth is held constant a fter the WEO projection period, a ssuming that this increase in health spending does notchange productivity.
} 


\section{The size of adjustments needed to meet the intertemporal budget constraint is} larger in countries facing higher interest rates and lower growth. High interest rates and low growth rates both reduce the amount of intertemporal liabilities and assets. Ceteris paribus, for a country with a primary deficit throughout the projection horizon (e.g., France, Japan and US) a larger interest-growth differential reduces the (negative) value of the cost of future policies and hence improves INFW, as the discounted value of the primary deficits decreases. However, if countries have primary surplus throughout the horizon, the opposite effect occurs, because larger interest-growth differentials also decrease the discounted value of primary surpluses.

\section{The adjustment needs are large, even under a relaxed solvency condition. For} each country, we first compute the size of the one-time permanent fiscal adjustment needed to bring the INFW to 0 . In other words, such adjustment would ensure that the future cost of policies exactly cancels out the current static NFW. For simplicity, we assume that growth and discount rates remain unchanged from the baseline. The resulting adjustment needs are sizeable for all countries. They range from 3.6 percent of GDP in Canada to over 10 percent of GDP in Japan - despite its INFW not being the largest among seven countries (Figure 13). We also compute the size of adjustments needed to equal only intertemporal part (i.e., present values of primary balances) to zero. This relaxes the solvency conditions of the budget constraint model by allowing the current static NFW to be carried over until the end of horizon. The adjustment needs are still significant, reaching 6.5 percent of GDP in the US, followed by 4.4 percent of GDP in Japan. In practice, any such adjustments would take place over a number of years. Our calculations suggest that if one were to make these adjustments gradually over a decade, the total adjustment need would only increase modestly from the numbers above (by 0.4-2.0 percentage points of GDP).

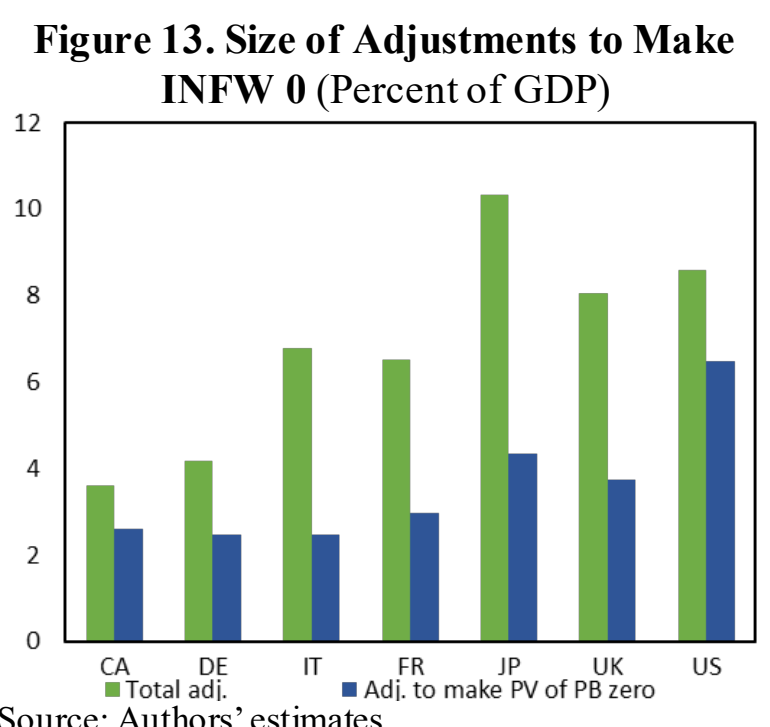

Source: Authors' estimates

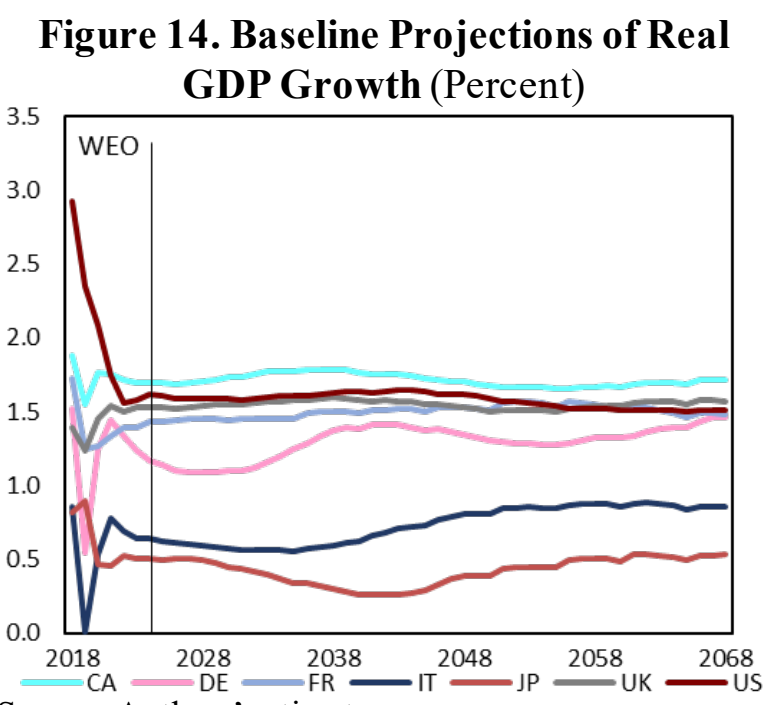

Source: Authors' estimates

26. These adjustment needs are in part driven by long-run growth outlooks. For Canada, Germany, France, UK, and US, real growth rates will be around $1 \frac{1}{2}$ percent in a 
long run, while for Japan and Italy real growth rates will remain around $1 / 2$ percent (Figure 14). After the WEO projection period, changes in real growth rates are driven only by demographic changes. ${ }^{12}$ At the end of the projection horizon, the OADRs of Canada, France, UK and US are projected to be between 42 and 48 percent, while the OADRs in Germany, Italy and Japan are projected to be 58,60 and 70 percent, respectively. Given the low growth in Japan, it faces larger interest-growth differentials than its peers, increasing the size of future primary surpluses needed to cancel out their negative static NFW.

\section{Sensitivity Analysis}

\section{Analyzing the sensitivity to} interest-growth differentials is helpful to gauge our assumptions on the discount rate. INFW is generally sensitive to changes in interest-growth differentials. However, the relation between INFW and interest rates is non-linear. Changing the discount rate (through a parallel shift of the interest rate path) shows that a decrease in the discount rate lowers INFW more than a similar increase in the discount rate improves INFW (Figure 15). This as future deficits increase the cost of future policy more than proportional when the discount rate drops. Appendix III provides further analysis of the INFW's sensitivity to interest rate changes.

\section{An alternative assumption on interest rates does not fundamentally alter the} picture, except for Japan. The alternative interest rate scenario applies the same long-run interest-growth differential to all seven countries. This implies different paths for interest rates in each country. ${ }^{13}$ In this scenario, individual country WEO interest rates projections are used for the medium-term, after which interest rates evolve to gradually increase the interestgrowth differentials to one percent by 2049 in each country (Figure 16). ${ }^{14}$ The results show modest changes in INFW for all countries bar Japan (Figure 17). This as for Japan the difference in the Year 50 discount rate between two scenarios is more than 2 percent, while for Canada, Germany, France, UK, and US less than 0.5 percent. Given the convex response of INFW to interest changes, Japan's INFW is impacted much more than that of peers,

\footnotetext{
${ }^{12}$ For exa mple, Italy's growth rates are projected to rise between 2040 and 2050 when its OADR peaks and begins decreasing. Germany's projected growth ra tes a lso flow from changes in its OADR.

${ }^{13}$ The historical trend of interest-growth differentials has been volatile for seven countries. While six out of seven countries had negative differentials in 2018, Barrett (2018) and Turner (2011) do not reject a possibility that the differentials will become positive in the future.

${ }^{14}$ This is a similar level a s the average differentials of seven countries between 1992 and 2018 ( 0.9 percent).
} 
becoming the worst among the G7 (at -389 percent of GDP). Even as the scenario represents a large change in interest-growth differential for Italy, its INFW does not change much, as Italy's path of primary balances is u-shaped, and hence its duration is lower than that of Japan.

Figure 16. Alternative Scenario of Interest-Growth Differentials (Percent)

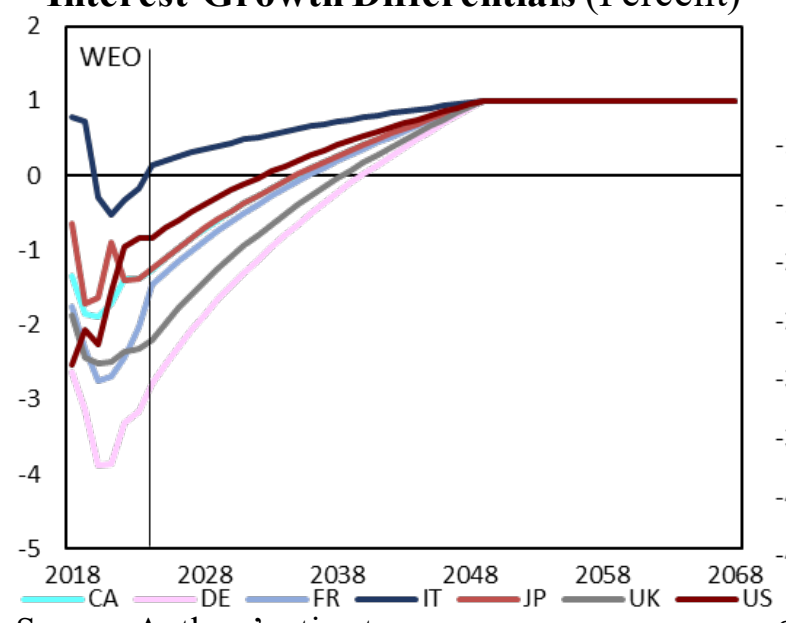

Source: Authors' estimates

\section{INFW is also sensitive to} assumptions on accelerated growth of per-person health spending. As shown in equation (5), per-person health spending is assumed to increase at growth rates of GDP per capita multiplied by acceleration factors $\left(\alpha^{65+}\right.$ and $\left.\alpha^{0-64}\right)$. Health spending projections are sensitive to assumptions on acceleration factors, which are applied throughout the horizon and thus have compounding effects. Historical data show that acceleration factors can fluctuate in a year by 0.5 point or greater. When we shift acceleration factors for spending of persons aged 65 years and over by \pm 0.5 point, the INFW changes by as much as 200 percent of GDP (Figure 18). Japan and Italy's INFW is less sensitive to acceleration factors than other countries, given their lower GDP per capita growth.

\section{Intertemporal Net Worth}

\section{We expand the concept of INFW to Intertemporal Net Worth (INW) by} incorporating nonfinancial assets. These nonfinancial assets include buildings, infrastructure, land, and natural resources. Many of these assets comprise the public capital 
stock and play an integral role in delivering economic and social outcomes; they are typically illiquid and difficult to dispose of. Over the long-term horizon considered in this paper, monetization (e.g., halting or decreasing maintenance and depreciating infrastructure away) is theoretically possible, if perhaps not advisable as it could negatively affect the economy and weaken the IPSBS as discussed below.

\section{We compute INW by replacing NFW with Net Worth (NW) in equation (1). ${ }^{15}$}

We furthermore add to equation (1) the term representing the discounted net investment in nonfinancial (produced) assets. This captures impact of capital investments in future years on the stock of nonfinancial assets, most of which do not generate direct revenue and thus are not included as assets when computing INFW. When computing net investments in future years (i.e., gross fixed capital formation minus consumption of fixed assets), we model a depreciation rate by taking into account a relationship between the life of assets and sufficiency of capital maintenance expenditure. Appendix IV details the methodology for estimating INW.

32. The G7's INW shows a similar picture to INFW. In the baseline case, gross fixed capital formation of general government is held constant at the 2018 level in terms of GDP. Present values of primary balances are the same as those included in the baseline INFW. All seven countries have negative INW in 2018, ranging from -36 percent of GDP in Canada to 249 percent of GDP in UK (Figure 19). This implies that none of seven countries meets their intertemporal budget constraint.

Figure 19. Intertemporal Net Worth, 2018 Figure 20. INW under Three Scenarios of
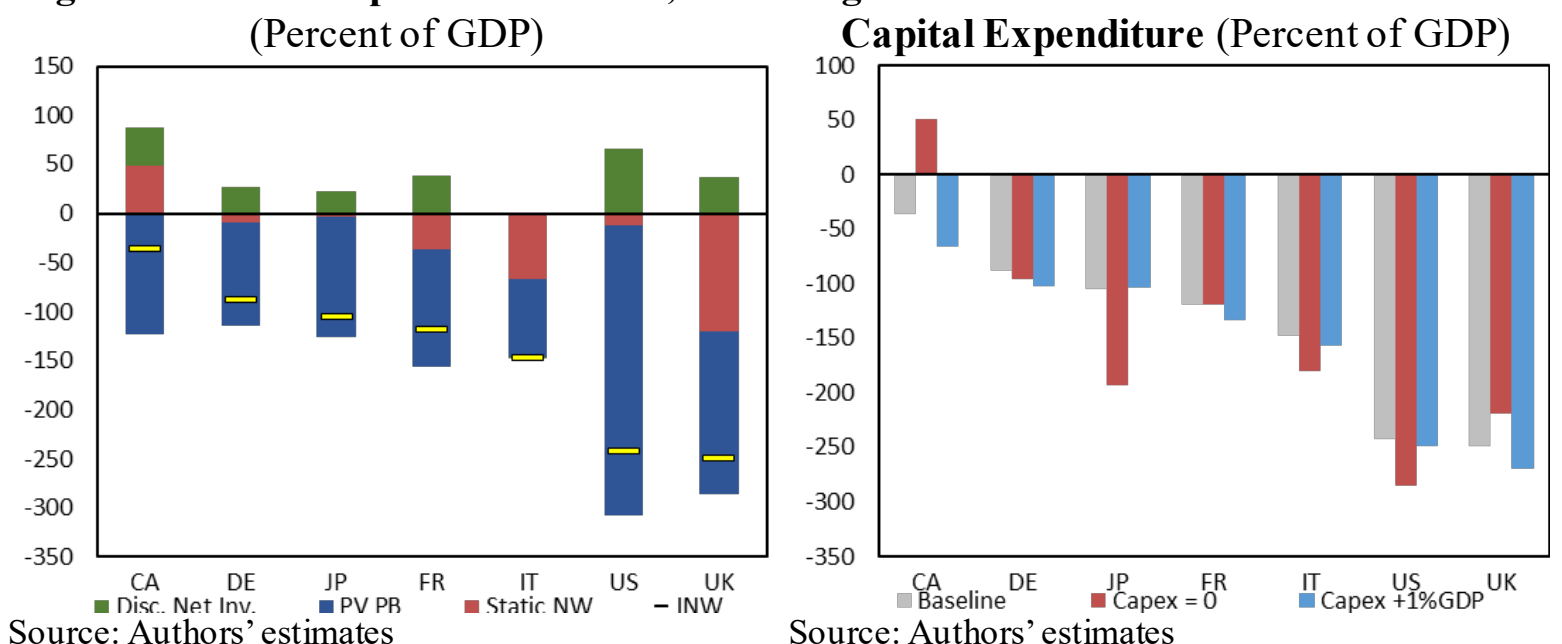

Source: Authors' estimates

\section{The INW level tends to worsen when monetizing nonfinancial assets, while it} generally remains unchanged when modestly increasing capital expenditure. To analyze the consequences of monetization of nonfinancial assets through halting maintenance we

\footnotetext{
${ }^{15}$ We hold nonfinancial assets constant in terms of GDP between 2016 and 2018, because updated data are not a vailable for all seven countries.
} 
compute INW under a scenario where no capital expenditure is made throughout the horizon. The results show that INW worsens in all countries except for Canada and UK (Figure 20), despite the lower capital outlays. ${ }^{16}$ In other words, the improvements of primary balances tend to be smaller than of the change in net investment. This policy would have further negative impact on INW, if other factors such as economic losses due to deteriorated infrastructures are incorporated. We also compute INW under a scenario where the level of capital expenditure is 1 percentage point of GDP higher at every point in time. In this scenario INW remains broadly unchanged from the baseline in all countries. That is, the decrease in primary balances and increases net investments associated with increase in capital expenditure virtually cancel each other out.

\section{The adjustment needs to meet the} intertemporal budget constraint based on the INW concept are still sizable. The adjustment needs are at 3.6 percent of GDP on average (Figure 21). Of course, for countries with a static NW close to zero (Germany, France, Japan, and US), the adjustment needs to make INW zero are at a similar level as those to make present values of primary balances zero.

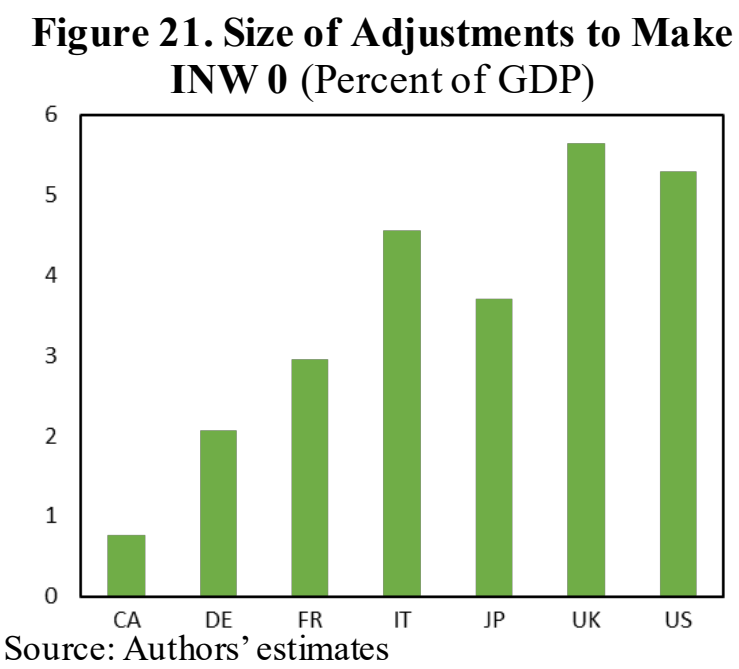

\section{Evolution OF G7's Intertemporal Public Sector Balance Sheet}

\section{This section examines evolution of G7's INFW and decomposes it into drivers of} changes. Analyzing historical INFW can shed light on important questions such as how unanticipated shocks (e.g., the 2008-09 global financial crisis) and following adjustments changed INFW in the past and what effects demographic shifts and associated policy reforms have had on IPSBS. The analysis is based on INFW time-series, developed in this paper for Canada, Japan, and UK. The choice of these three countries was driven by data availability, in particular long timeseries of static PSBS data and vintage general government fiscal projections in the WEO. ${ }^{17}$

\footnotetext{
${ }^{16}$ In Canada and UK, stopping capital expenditure improves INW, a s the level of general government fixed a ssets in their sta tic balance sheets is rela tively low at 30 and 41 percent ofGDP in Canada and the UK respectively.

${ }^{17}$ In this cha pter, we compute only evolution of INFW. A long time-series data ofnon-financial assets, which a re needed to compute evolution of INW, a renot available for a ll three countries.
} 
36. Historical INFW is estimated by incorporating and reproducing vintage macrofiscal projections over a 50-year horizon. Computation of historical INFW follows the methodology described in Section II. Population projections are derived from the vintage UN World Population Prospects latest available for past years. ${ }^{18}$ For the medium-term (Year 1 to 6 ), we base projection on the vintage macro-fiscal projections of the historical WEO vintages. ${ }^{19}$ For the long-term (Year 7 to 50 ), output projections are made by following equation (3). Primary revenue and expenditure other than health and pension expenditure is held constant its Year 6 level (as share of GDP). Projections for health and pension expenditure follow the equations (4) and (5). For pension projections, assumptions on coverage and replacement rates incorporate the effects of pension reform measures that were implemented or on the book in past years. For health projections, assumptions on acceleration factors are derived from the moving averages for three to eight years. ${ }^{20}$

\section{In estimating historical INFW, interest rates are assumed to converge to the} level that makes the interest-growth differential equal to one percent in the long-run. These assumptions are same as the alternative interest rate scenario in Section III. ${ }^{21}$ Paths of interest rates incorporate projections of the historical WEO vintages for the medium-term and beyond Year 6 gradually converge to a one percent interest-growth differential in Year 31 , where they are held constant afterward.

38. Annual changes in INFW are decomposed into five main drivers. We decompose annual changes in INFW into five factors, including (i) medium-term levels of primary balances, (ii) policy parameters of pension projections (coverage and replacement ratios), (iii) acceleration factors of health projections, (iv) population projections, and (v) a residual, which is mainly associated with growth. The decomposition is done by computing alternative INFWs, changing only one specific factor while keeping other assumptions constant.

\section{Short-term changes in INFW are driven by fiscal policies, rather than changes in} growth or demographic outlooks. The levels of INFW can change significantly in a shortperiod of time. The size of the largest annual changes in INFW between 1989 and 2018 were

\footnotetext{
${ }^{18}$ We incorporate World Population Prospects published in the following years: 1992, 1994, 1996, 2000, 2002 , $2004,2006,2008,2010,2012,2015$ and 2017. Because the projections were updated at two to three-year frequencies, we assume that population outlooks remain the same between the updates.

${ }^{19}$ IMF WEO projections are a vaila ble atsemiannual frequencies from 1990 to 2019. This section uses October projections.

${ }^{20}$ The moving a verage for eight years is used for a cceleration factors of per-person health spending by population below 64 years old. The moving a verage for three years is used for a cceleration factors of per-person health spending by population above 65 years old, as this item reacts faster to changes in health policy. When the moving a verage is below 1 , acceleration factors a re a ssumed to be 1 . To a void explosive projections, a ceiling on a cceleration factors is set for each country. When health policy guarantees a minimum growth rate of per-person health spending (e.g. Japan), a cceleration factors are set by combining the minimum growth rate and expected long-run nominal growth rates.

${ }^{21}$ We choose these a ssumptions because the projected long-term interest rates used in the baseline in Section III a re dependent variables in the empirical estimation in Section V.
} 
+110 percent of GDP in Canada (1994), -173 percent of GDP in UK (2001), and -194 percent of GDP in Japan (2008). The decomposition shows that by far the largest portion of these changes stems from fiscal policies. In particular, changes in medium-term levels of primary balances are the largest contributors to annual changes in INFW. The effects of health policy changes, captured as changes in acceleration factors, are also important contributors. Changes in growth or interest rates or demographic outlooks had less influence on short-term fluctuations of INFW.

40. Canada's INFW has gradually improved in recent years. ${ }^{22}$ INFW improved to around -90 percent of GDP in the late 1990s (Figure 22). Decomposition of annual changes show that this improvement was due mainly to deficit reduction measures taken by both the federal and provincial governments (Figure 23). In the early 2000s, however, INFW worsened to below -300 percent of GDP, mostly due to changes in health policy. Specifically, during the period of "reinvestment" in the health sector, which was agreed in the 2004 health accord between the federal and provincial-territorial governments, the health and social transfers to provinces from the central government increased, leading to an acceleration of the increase in per capita health spending. After the global financial crisis, INFW improved once again, returning to its 1989 level. In particular, as part of deficit reduction measures, tightening of health policy played an important role. In contrast, pension policy has had little impact on evolution of Canada's INFW in the absence of major reforms.

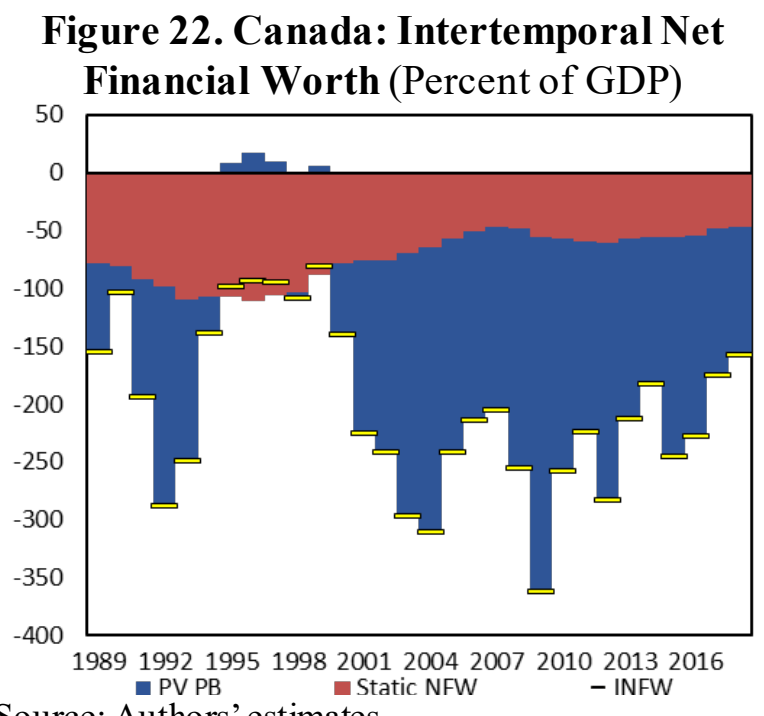

Source: Authors' estimates

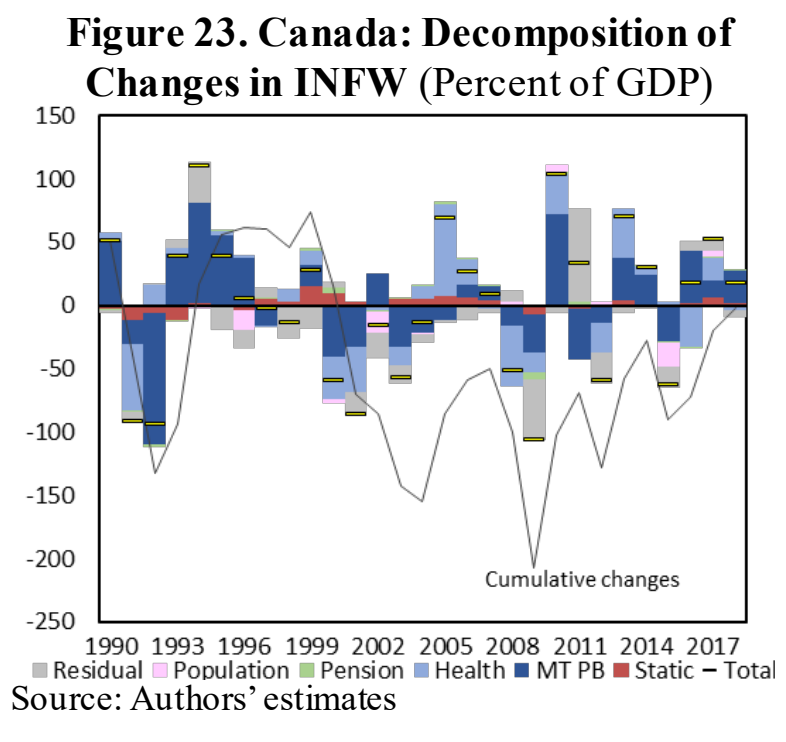

Figure 23. Canada: Decomposition of

\section{Fiscal policy in Japan has not turned around the deteriorating trend of INFW.}

Since 1990, when INFW became close to breakeven (-33 percent of GDP), INFW has worsened by more than 300 percent of GDP (Figure 24). Between 1991 and 1994, INFW was brought down by around 50 to 100 percent of GDP every year, as a result of persisting fiscal

\footnotetext{
${ }^{22}$ This para graph is ba sed on Kneebone et. al.(1999), Rocher and Smith (2002), Matier(2012), and Canadian Institute for Health Information(2020).
} 
expansion after the burst of asset price bubbles (Figure 25). In the early 2000s, a series of pension reforms had a positive impact on INFW, ${ }^{23}$ but the increase in the medium-term primary deficits in 2002 and 2008 in response to the Japanese and global financial crisis brought about a much larger decrease in INFW. ${ }^{24}$ Health spending also had sizable negative impact on INFW after 2000, when new long-term care insurance was introduced. Per capita nominal health spending on people older than 65 years has grown steadily by 1.5 percent per year on average between 2000 and 2018, during which time GDP per capita grew by just 0.2 percent per year on average. This as existing health policy assumes an increase of health spending up to a growth rate of old age population, which has been higher than economic growth rates. ${ }^{25}$ In tandem, after 2010 long-term growth potential of the economy declined from around 1.8 percent to $1 / 2$ percent.

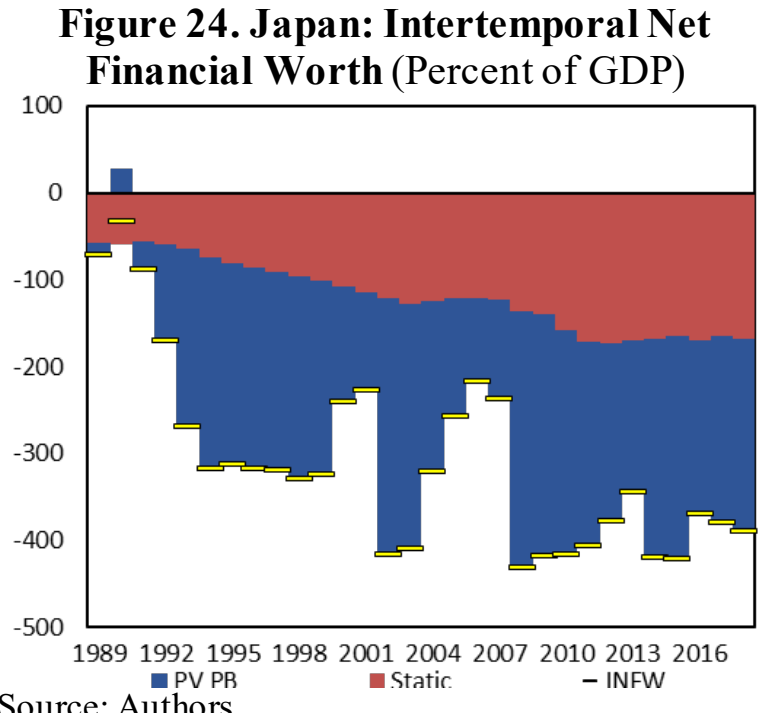

Source: Authors

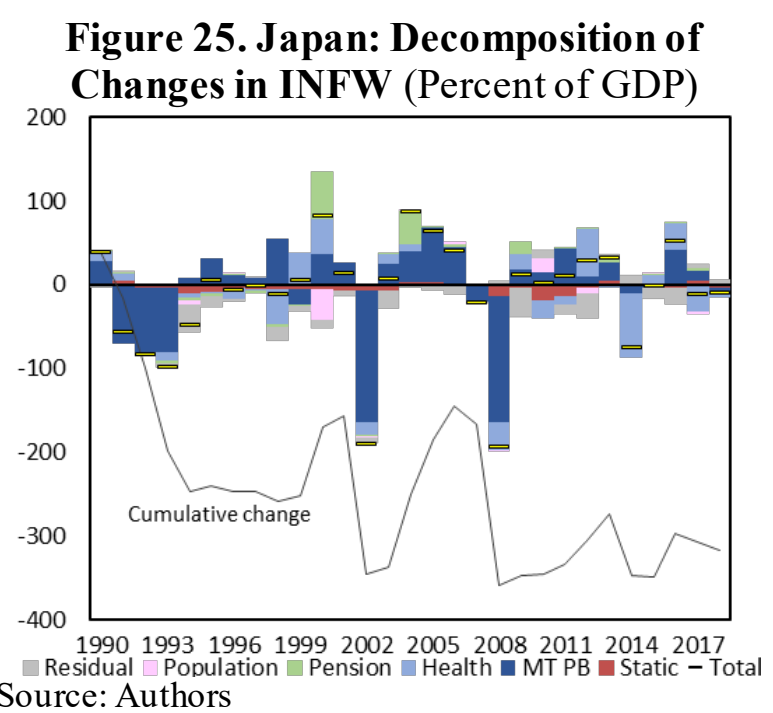

Figure 25. Japan: Decomposition of

42. UK's INFW has swung around, driven by fiscal consolidation and expansive health policy (Figure 26). ${ }^{26}$ In the 1990s, expenditure reduction measures, including the introduction of the Spending Review process, turned medium-term primary balances into surplus and improved INFW from -289 percent of GDP at the time of the 1992 economic

\footnotetext{
${ }^{23}$ The pension reforms include, a mong others, (i) a gra dual increase of the pension eligibility a ge for the Employee's Pension from 60 to 65 between 2001 and 2013 and (ii) the introduction of the "macroeconomic slide" fra mework, which a djusts a level of pension ben efits based on wa ge growth, inflation, decrease in working a ge population, and life-expectancy, every year until 2043. See Koshima (2019).

${ }^{24}$ In 2002 at the peak of the Japanese financial crisis, the government postponed the objectives to achieve primary surplus by the early 2010s ("Reform and Outlook - 2002 Revision" by the Cabinet in Ja nuary 2003).

25 "Basic Policy on Economic and Fiscal Management and Reform 2018" (Cabinet, June 2018). The population a bove 65 years old grew by 2.3 percent per year on average between 2010 and 2019 . This policy effectively a ssumes a minimum increase of per-person health spending. The recent long-term projections of health spending by the government a ssume that a unit price of health ca re grows at a rate of "economic growth $\times 1 / 3+$ $1.9 \%-0.1 \% "$ (Cabinet Office, May 2018).

${ }^{26}$ This para graph is ba sed on Crawford et. al. (2018) and Thorlby and Maybin (2010).
} 
crisis to -82 percent of GDP in 1999 (Figure 27). However, after the announcement of the National Health System 2000 Plan, which expanded deliveries of public healthcare services, growth of per capita nominal health spending on people over 65 years old speeded up from 5 percent per year on average between 1993 and 1999 to 8 percent per year on average between 2000 and 2009. This policy wiped out the positive effects of expenditure reduction measures and brought INFW down to below -355 percent of GDP in 2002. ${ }^{27}$ After the global financial crisis and the immediate associated large primary deficits, fiscal consolidation efforts gradually improved the medium-term primary surplus and INFW to above -200 percent of GDP in 2013. Nonetheless, the 2018 announcement that expands the National Health System spending again drove INFW down to -352 percent of GDP at end 2018. Although since the 1990s the government has undertaken a series of state pension reforms, they did not have consistent impact on INFW. Some reforms, such as increase in pension ages, ${ }^{28}$ had a positive impact, but others, such as the introduction of the "triple lock" ${ }^{29}$, had a negative impact.

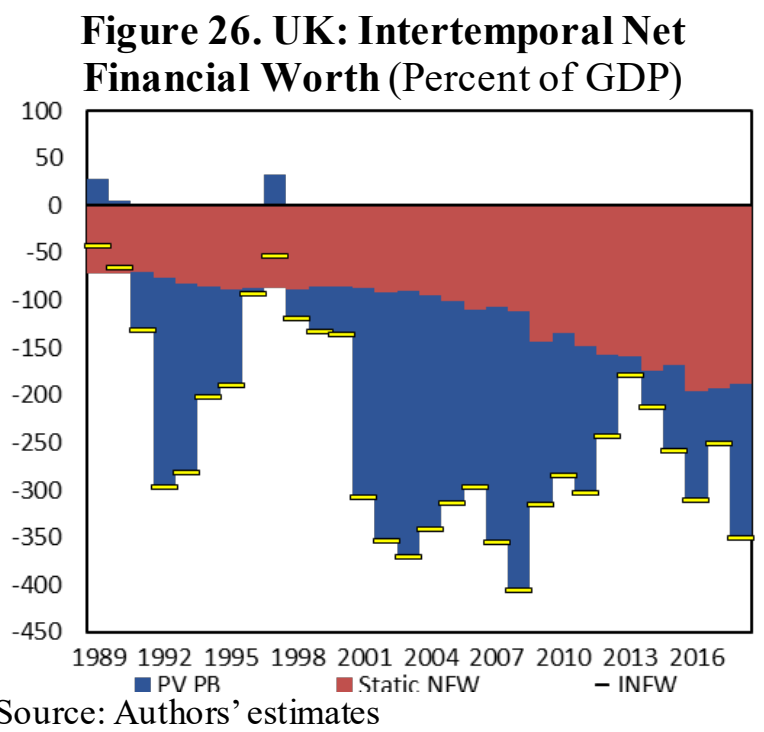

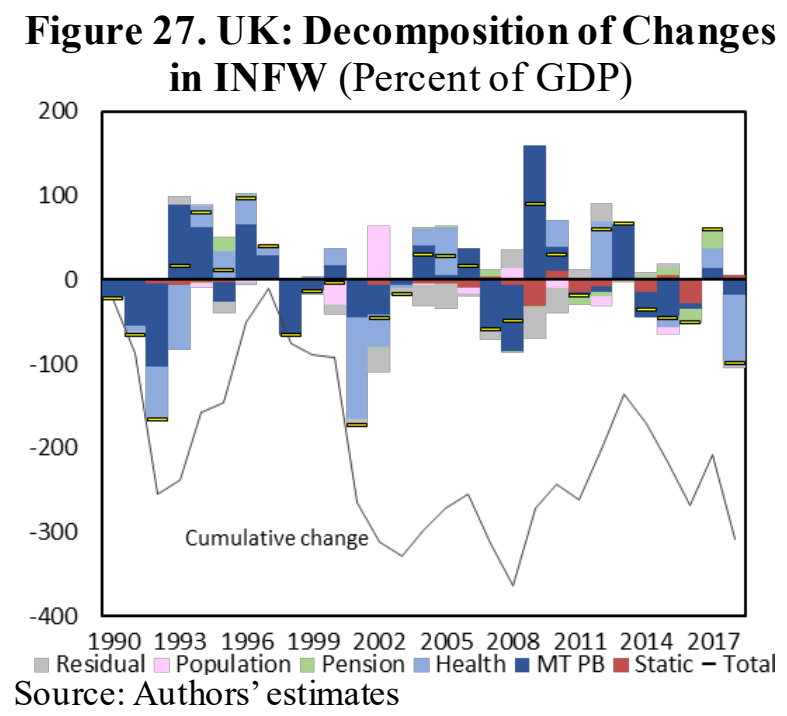

\footnotetext{
${ }^{27}$ Under the unchanged policy assumption, this accelerated growth rate of per-person health spending is carried forward throughout the projection horizon. As a result, the levelof projected health spending in Year 50 jumps from 8.5 percent of GDP in 1999 projections to 20.3 percent of GDP in 2002 projections.

${ }^{28}$ On Sta te pension ages, the Pension Act 1995 gradually increased women's pension a ges from 60 to 65 between 2010 and 2020. The Pension Act 2007 increased pension a ges of both men and women to 66 between 2024 and 2026, to 67 between 2034 and 2036, and to 68 between 2044 and 2046. The Pension Act 2011 a ccelerated increase in women's pension ages, which reach 65 in 2018 , and increase in pension ages of both men and women, which reach 66 in 2020. The Pension Act 2014 further a ccelerated the increase to 67 to 2028 . The State pension age review a lso brought forward the increase to 68 to 2038.

${ }^{29}$ Under the "triple lock" introduced in 2011, the government increases the State pension benefits at the highest rate of a verage earnings, CPI, or fixed percentage (2.5\%).
} 
43. Drivers of cumulative long-term changes in INFW show which policy measures had the most long-lasting impact. Drivers of long-term changes in INFW levels are different from those of the short-term fluctuations discussed above. The factors that contributed less to annual changes in INFW, such as growth outlooks (shown as residual) and demographic projections, have a very visible impact on INFW in the long run (Figure 28). In UK, changes in medium-term primary balances did not have long-lasting impact, because periods of fiscal consolidation tended to be
Figure 28. Cumulative Changes in INFW

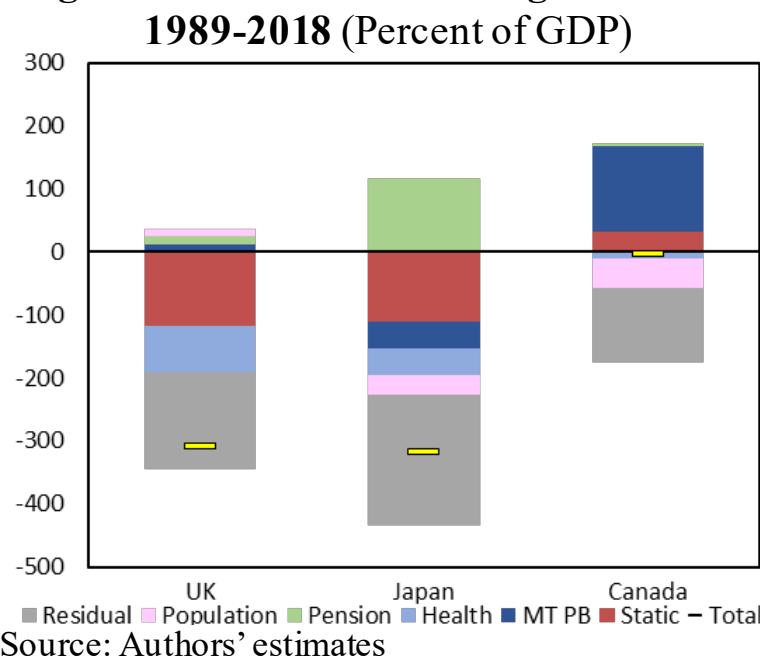
followed by periods of expansion and effect cancelled out over the long run. Instead, the expansive health policy has had a persistent negative impact on INFW. In Japan, pension reforms have had significant positive cumulative effects on INFW. However, these were offset by the persistent negative impact of fiscal expansion as well as the expansion of heath policy for an aging population, including the introduction of long-term care insurance. Unlike these two countries, in Canada, fiscal consolidation efforts have had a consistent positive effect on the long-run developments of INFW. Pension and health policy had little cumulative influence on Canada's INFW.

\section{INFW AND BORROWING COSTS}

\section{This section estimates the long-run relationship between INFW and government} borrowing costs. The empirical analysis is based on the INFW time series developed above for Canada, Japan, and UK. We examine the relationship between INFW and slopes of future 1-10-year government bond yield curves.

\section{The existing literature suggest there may be some relationship between the} intertemporal budget balance, fiscal policy, and the interest rates government pay on their borrowing. Trehan and Walsh (1988) and Bohn (1998) argue that the U.S. fiscal policy responds to the intertemporal budget constraint in the long run. IMF (2018), Gonguet and Hellwig (2019), and El Rayess et. al. (2019) all present fiscal sustainability analyses based on INFW. A major challenge in estimating an explicit relationship between fiscal variables (such as debt and deficits) and government bond yields arises from the fact that both interest rates and fiscal variables are endogenous to the business cycle (Gruber and Kamin, 2010). ${ }^{30}$

\footnotetext{
${ }^{30}$ For exa mple, during a recession, the government may increase fiscal deficits, which ra ise a government debt level, while interest rates may drop due to the monetary easing, resulting in a positive correlation between primary bala nces and interest rates.
} 
Laubach (2003), Gruber and Kamin (2010), and Gamber and Seliski (2019) address this endogeneity problem by focusing on a relationship between interest rates and medium-term fiscal projections. Laubach (2003) found that for the US a percentage increase in the CBO and OBM projections of deficit- and debt-to GDP ratios raises future interest rates by 20-40 basis and $4-5$ basis points respectively. Gamber and Seliski (2019) obtained similar results by using more recent projections. Gruber and Kamin (2010) also found a statistically significant relationship between long-term interest rates and OECD macro-fiscal projections of 19 countries. Related literatures suggest a relationship between fiscal policy and slope of yield curves. By using OECD countries' data, Reinhart and Sack (2000) found that a percentage improvement to deficit-to-GDP ratios projected in the budget flattens the yield curve by 9 basis points.

\section{Policymakers also increasingly take account of intertemporal fiscal} sustainability. Hughes (2019) argues that estimates of intertemporal balances are increasingly used to inform fiscal policy discussions. OBR (2018) shows how INFW captures not only levels of future primary balances, but also the impact of different paths to achieve these balances, and its implications for long-term fiscal sustainability. The Fiscal Sustainability Reports of the UK OBR include estimation of intertemporal "fiscal gaps" and the impact of different adjustment measures. The Long-Term Budget Outlooks of the US $\mathrm{CBO}$ also include similar intertemporal estimation, particularly for the analysis of social security programs. The incorporation of INFW into policy would be further encouraged if financial markets also take it into account when pricing government bonds.

\section{Modeling the relationship between INFW and government borrowing cost has} advantages. A model based on static NFW captures the effects of balance sheet strength beyond debt on government borrowing costs. This is illustrated in IMF (2018) and Yousefi (2019), who found that a 10 percentage point of GDP increase in (static) NFW lowers long term government bond yields by around 9 basis points in advanced economies (while controlling for debt levels). These effects suggest that financial markets to some extent consider public sector assets in pricing government bonds. A model based on INFW expands the analysis to intertemporal assets and liabilities. This would shed light on whether financial markets also pay attention to financing of future obligations from future revenue, in addition to accumulated (i.e. current static) assets.

\section{The estimation in this paper regresses spreads between future short and long-} term interest rates on INFW. As noted above, some existing literatures use market-implied future interest rates for regression to separate short-term effects of business cycles from longterm effects of other factors on interest rates. Following to this approach, we use ten-year 
ahead spreads between one and ten year interest rates. ${ }^{31}$ Under the rational expectations hypothesis, this would be equal to the difference between one and ten year rates in year 10 , with the 10-year rate itself a function of the average expected one-year rates between years 11 and 20. However, in reality the yield curve also includes market's views on credit and interest rate risks in short-term rates.

\section{The model specification is as follows:}

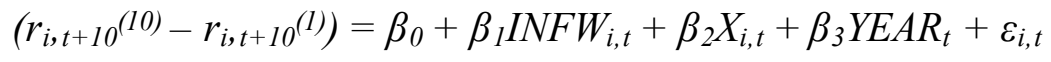

where $r_{i, t+10^{(10)}}$ and $r_{i, t+10^{(1)}}$ are respectively the projected ten-year-ahead ten-year and oneyear interest rates of country $i$ at time $t$ and $I N F W_{i, t}$ is INFW of country $i$ at time $t$. The tenyear-ahead ten-year and one-year rates are computed respectively as implied forward rates between 20-year and ten-year spot rates and 11 -year and ten-year spot rates. ${ }^{32}$ INFW data are those derived above. The sample period is from 1989 to 2018 and the sample of countries consists of Canada, Japan, and UK, for which we constructed INFW time-series. The vector $X_{i, t}$ contains additional control variables. Following from Yousefi (2019) and Poghosyan (2012), they include growth rate of per capita real GDP and changes in CPI, which aim to isolate effects of short-term real and nominal shocks; and general government net lending and debt (both as share of GDP), which are to isolate the effects of short-term fluctuations of fiscal variables. ${ }^{33}$ Data on control variables are obtained from the IMF WEO database. $Y E A R_{t}$ is a year dummy to control time effects.

\section{Our choice of regression techniques takes into account cross-section correlation}

and the limited size of the panel. The results of Pesaran Cross-section Dependence tests reject the null hypothesis of cross-sectional independence at a significance level of 1 percent for four out of six variables. Using feasible generalized least square (FGLS) addresses crosssectional correlation issues. Beck and Katz (1995) argue that FGLS has tendency to generate optimistic standard errors when $\mathrm{T}$ (number of time points) is not sufficiently larger than $\mathrm{N}$ (number of units) included in the panel. In our case, a panel has relatively long time-series (30 years) but contains only three countries. This results in a large $\mathrm{T}$ to $\mathrm{N}$ ratio (10).

Generally, FGLS features the limitation that the estimation does not include individual fixed

${ }^{31}$ The response variable is calculated by the following formula of implied forward rates:

$$
r_{10}^{(10)}-r_{1}^{(10)}=\left(\frac{\left(1+r_{20}\right)^{20}}{\left(1+r_{10}\right)^{10}}\right)^{\frac{1}{10}}-\frac{\left(1+r_{11}\right)^{11}}{\left(1+r_{10}\right)^{10}}
$$

$\left(\mathrm{r}_{\mathrm{t}}{ }^{\mathrm{k})}\right.$ and $\mathrm{r}_{\mathrm{t}}$ respectively denote $\mathrm{k}$-year ahead $\mathrm{t}$-year ra tea nd $\mathrm{t}$-year spot rate)

\footnotetext{
${ }^{32}$ Spot rate data are derived from websites of theBank of Canada, the Japan's Ministry of Finance, and the Bank ofEngland.

${ }^{33}$ We use per ca pital rea lGDP and general government net lending, instead of real GDP growth and general government primary balances, both of which are included in computation of INFW. We also do not include short-term interestrates, a sa dependent variable is implied forward rates, which eliminate the effects of shortterm fluctuations of long-term rates. Yousefi(2019) includes US trea sury ten-year yields as a further control to isola te the impact of US financial markets. Because the level of correlation between domestic a nd US long-term rates varies across countries (Caceres et. al.,2016), we run regressions excluding this control variable.
} 
effects. However, we show below that for our panel the FGSL and fixed effect estimation generate similar coefficients. Therefore, for our baseline estimation we use FGLS with assumptions of heteroskedastic error structure with cross-sectional correlation, while employing other regression techniques for robustness checks.

\section{The baseline estimation results suggest the existence of a relationship between} INFW and spreads between future long- and short-term interest rates. The coefficients on INFW are statistically significant and economically meaningful (Table 1). They suggest that a 10-percentage increase in INFW (in terms of GDP) reduces spreads between ten-year ahead ten-year and one-year government bond yields by 2.8 basis points. This effect is meaningfully different from zero, given that INFW can swing by 200 percent of GDP, which would imply interest rate changes of over 0.5 percent points. The coefficients of control variables are generally not statistically significant. Similar results are obtained when we use lagged explanatory variables.

\begin{tabular}{|c|c|c|}
\hline & Without lag & With lag(1) \\
\hline INFW & $\begin{array}{l}-0.0028 \text { ** } \\
{[0.0011]}\end{array}$ & $\begin{array}{l}-0.0026 \text { ** } \\
{[0.0011]}\end{array}$ \\
\hline Real GDP per capita growth & $\begin{array}{r}0.1020 \\
{[0.0664]}\end{array}$ & $\begin{array}{r}0.0895 \\
{[0.0661]}\end{array}$ \\
\hline CPI change & $\begin{array}{r}0.0283 \\
{[0.0779]}\end{array}$ & $\begin{array}{r}-0.0452 \\
{[0.0777]}\end{array}$ \\
\hline General gov't net lending & $\begin{array}{c}0.0571 \\
{[0.0336]}\end{array}$ & $\begin{array}{c}0.0652 \\
{[0.0339]}\end{array}$ \\
\hline General gov't debt & $\begin{array}{r}0.0033 \\
{[0.0022]}\end{array}$ & $\begin{array}{r}0.0034 \\
{[0.0022]}\end{array}$ \\
\hline Constant & $\begin{array}{c}-1.239 \\
{[0.4685]}\end{array}$ & $\begin{array}{r}-0.699 \\
{[0.4720]}\end{array}$ \\
\hline $\begin{array}{l}\text { Observations } \\
\text { Number of countries } \\
\text { Year dummies } \\
\end{array}$ & Yes & Yes \\
\hline
\end{tabular}

Source: authors' estimates

Standard errors are shown in parentheses below the coefficient estimates. $* * *$ denotes significance at the 0.01 level, ** denotes at the 0.05 level, and * denotes at the 0.1 level.

\section{Robustness Checks}

52. We apply various robustness checks. First, we use fixed effect estimation with country and year fixed effects. The results show that coefficients of INFW still have appropriate signs but are not statistically significant (Table 2). Second, Ordinary Least Square estimation with panel-correlated standards errors, which is an alternative technique to address heteroskedasticity and correlation across panels, also generates similar results. Third, the country-specific estimation shows mixed results. Fourth, we use data on the estimated 
term premium from Bauer (2014) as explanatory variable. ${ }^{34}$ While the sample period is limited to 1990-2008, the results show coefficients of similar level and statistical significance as our baseline, confirming a relationship between INFW and interest rate spreads. We also run unit root tests. Panel unit root tests reject the null hypothesis that all panels are nonstationary for all variables at 1 to 10 percent significance levels, except for general government debt (Table 3). ${ }^{35}$ All these results are affected by the limited number of countries included in the panel. Future work on a larger number of counties once data becomes available may alleviate these issues.

Table 2. Fixed Effects and Country Specific Estimates: Dependent Variable $\left(r_{i, t+10^{(10)}}-r_{i, t+10^{(l)}}\right)$

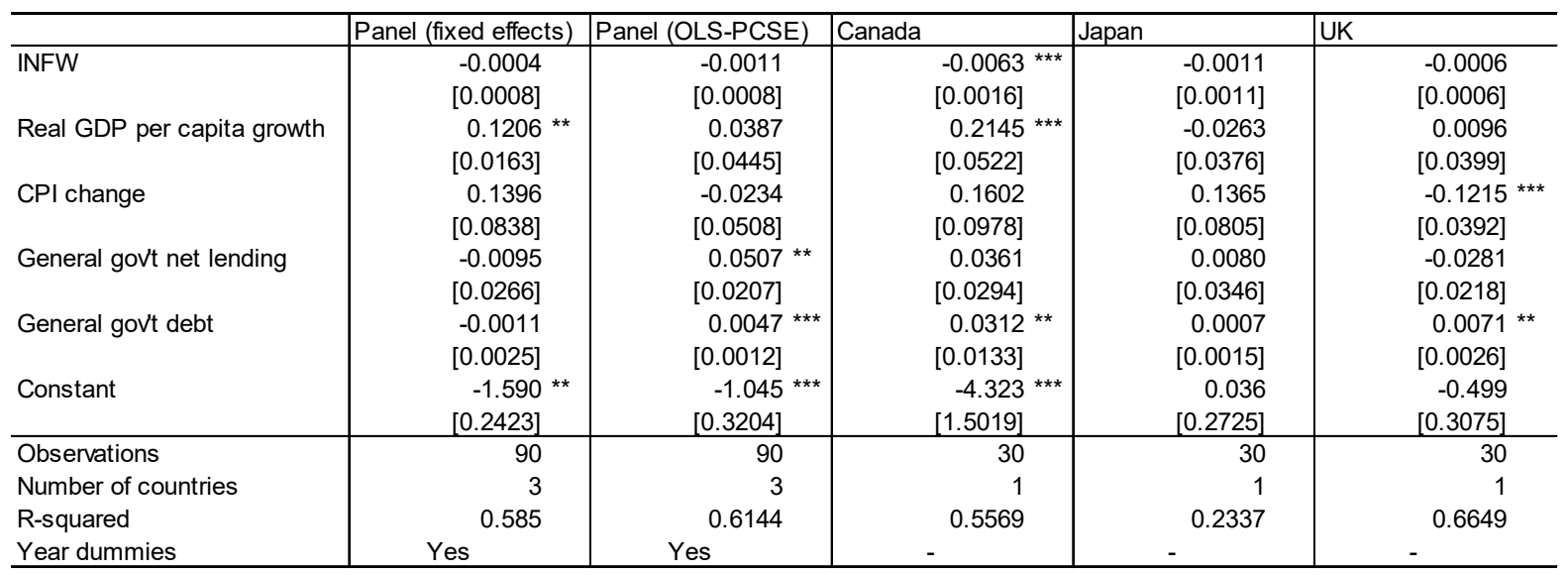

Source: authors' estimates

The first column shows the results of fixed effect estimation with country and year fixed effects and robust standard errors. The second column shows the results of OLS estimation with panel-correlated standard errors. The next three columns show the results of country specific estimation. $* *$ denotes significance at the 0.01 level, ** denotes at the 0.05 level, and $*$ denotes at the 0.1 level.

Table 3. Unit Root Tests (P-Value)

\begin{tabular}{l|r|r|r|r|r|r}
\hline & $\begin{array}{c}r_{i, t+10^{(10)}} \\
r_{i, t+10^{(1)}}\end{array}$ & \multicolumn{1}{|c|}{ INFW } & $\begin{array}{l}\text { Real GDP per } \\
\text { capita growth }\end{array}$ & CPI change & $\begin{array}{c}\text { General gov't } \\
\text { net lending }\end{array}$ & $\begin{array}{c}\text { General } \\
\text { gov't debt }\end{array}$ \\
\hline Fisher & 0.0000 & 0.0385 & 0.0000 & 0.0000 & 0.0017 & 0.5874 \\
\hline Im-Pesaran-Shin & 0.0001 & 0.0560 & 0.0002 & 0.0063 & 0.2791 & 0.9607 \\
\hline
\end{tabular}

Source: authors' estimates

\footnotetext{
${ }^{34}$ The term premium is defined a s difference between long-term spot rates minus thea verage of expected shortterm rates. It reflects investors' demands of compensation for increased credit and interest risks that comes with lending for longer periods.

${ }^{35}$ When we include the first difference of general government debt instead of its level in the model, INFW still has a coefficient of similar level and statistical significance.
} 


\section{Conclusions}

53. We derive intertemporal balance sheets for the G7 countries, finding that on current policies, all $\mathbf{G} 7$ countries fall well short of their respective intertemporal budget constraints. The average INFW across the G7 is minus 267 percent of GDP, with none of the countries having sufficient fiscal resources to meet their spending promises under current policies. While common across the $\mathrm{G} 7$, this result is not an inevitable result for advanced economies with ample access to credit markets and well-developed social security systems. Similar analyses for Norway, Finland and New Zealand find positive, or only slightly negative estimates of intertemporal net worth (Brede and Henn, 2019, Cabezon and Henn.,2019, and New Zealand Treasury, 2018). Among the G7, US shows the largest shortfall, with an INFW worth of minus 392 percent of GDP, and Canada the smallest, at minus 170 percent of GDP. These shortfalls are driven by negative NFW at the outset (i.e., they countries currently already owe more than they own) and growing future health obligations in light of population aging. Closing these gaps would require adjustments to the primary balance of an average of almost 7 percent of GDP. The size of these adjustments varies across countries, with Japan requiring the largest adjustment, and Canada the smallest. Importantly, these adjustments are not necessarily proportional to the size of the INFW shortfall (or current debt levels), owing to a combination of varying interest and growth differentials across countries.

\section{For three of the countries, data availability allows a decomposition of the} evolution of INFW over time, generally showing deterioration over time, characterized by large fluctuations. Over the past 40 years Japan and UK have recorded INFW deteriorations in excess of 300 percent of GDP, while Canada's INFW ended largely where it began. However, all three experienced large fluctuations, with swings of the order of 200 percent of GDP in both directions not uncommon. The large short-term fluctuations are mostly driven by fiscal policy changes, such as the UK's fiscal consolidation in mid 1990s, followed by the relaxation in the early 2000 s, while demographic developments and associated health obligations lead to a steady long-run deterioration. These decompositions also demonstrate the large impact that small but long-standing policy changes to pensions and health can have on long-run fiscal sustainability.

55. We find a relationship between long-term interest rates on sovereign borrowing and the strength of a country's intertemporal balance sheet. On average, a 10-percentage point of GDP increase in INFW reduces spreads between future 1 and 10 year yields of government bonds by 2.8 basis points. This implies that when INFW improves interest rate spreads tend to decrease, possibly reflecting markets participants' views that higher INFW lowers credit and interest risks. These results control for government deficits and the level of debt, suggesting the effects we find are over and above the effects of standard fiscal metrics.

56. Further research on INFW could promote the balance sheet approach to fiscal policy assessment. Analysis of evolution of INFW in three countries suggests that the 
2008-09 global financial crisis had a differential impact on the intertemporal PSBS, depending on the fiscal crisis response and recovery. Future work can similarly assess the ways in which IPSBS has been influenced by the shock to public finances and growth from the COVID-19 pandemic, including through economic scarring effects. Our findings extend the result in Yousefi (2019) and IMF (2018) that showed the influence of static balance sheet strength and public assets on long-term government bond yields to intertemporal balance sheets. Contrary to mainstream economic orthodoxy, our estimation results suggest that financial markets do provide signals on the sustainability of long-term government policy obligations related to future health and pension spending in relation to projected future revenue, over and above to current government assets and liabilities. However, the limited sample size poses some challenge for the robustness of estimation. Expanding the analysis of INFW to more countries would allow more firm conclusions on financial markets role in signaling long-run sustainability of public finances. 


\section{APPENDIX I. METHODS FOR UPDATING NET FINANCIAL WORTH}

\begin{tabular}{|l|l|}
\hline \multicolumn{1}{|c|}{ Country } & \multicolumn{1}{c|}{ Methods and Data Sources } \\
\hline $\begin{array}{l}\text { Canada, Japan, } \\
\text { UK, UK }\end{array}$ & $\begin{array}{l}\text { NFW figures are updated by following the same methods and data } \\
\text { sources specified in the metadata documents of the IMF PSBS database. }\end{array}$ \\
\hline $\begin{array}{l}\text { France, } \\
\text { Germany }\end{array}$ & $\begin{array}{l}\text { NFW figures are updated by following the same methods and data } \\
\text { sources specified in the metadata documents of the IMF PSBS database. } \\
\text { General government financial assets and liabilities (except for civil } \\
\text { service pension liabilities) are derived from the Eurostat database. }\end{array}$ \\
\hline Italy & $\begin{array}{l}\text { Figures of Italy, which are not included in the PSBS database, are } \\
\text { derived from De Angelis et. al. (forthcoming) }\end{array}$ \\
\hline
\end{tabular}




\section{APPENDIX II. UNDERLYING ASSUMPTIONS FOR BASELINE CASE}

\section{Canada}

\begin{tabular}{|c|c|c|c|c|c|c|c|}
\hline & 2018 & 2024 & 2030 & 2040 & 2050 & 2060 & 2068 \\
\hline \multicolumn{8}{|l|}{ Demographic projections } \\
\hline Old-age dependency ratio $(65+/ 15-64)$ & 0.26 & 0.32 & 0.38 & 0.42 & 0.44 & 0.47 & 0.48 \\
\hline \multicolumn{8}{|l|}{ Macroeconomic assumptions } \\
\hline Real GDP growth rate & 1.88 & 1.70 & 1.73 & 1.77 & 1.67 & 1.67 & 1.72 \\
\hline Growth rate of labor & - & 0.25 & 0.31 & 0.38 & 0.20 & 0.18 & 0.28 \\
\hline Growth rate of hours worked & - & 0.54 & 0.54 & 0.54 & 0.54 & 0.54 & 0.54 \\
\hline Growth rate of capital stock & - & 2.34 & 2.34 & 2.34 & 2.34 & 2.34 & 2.34 \\
\hline Growth rate of total factor productivity & - & 0.15 & 0.15 & 0.15 & 0.15 & 0.15 & 0.15 \\
\hline Labor share & $\begin{array}{r}0.51 \\
\text { (Av. 2014-18) } \\
\end{array}$ & 0.51 & 0.51 & 0.51 & 0.51 & 0.51 & 0.51 \\
\hline Nominal GDP growth rate & 3.62 & 3.81 & 3.85 & 3.88 & 3.79 & 3.78 & 3.83 \\
\hline Deflator change rate & 1.71 & 2.08 & 2.08 & 2.08 & 2.08 & 2.08 & 2.08 \\
\hline \multicolumn{8}{|l|}{ Fiscal projections } \\
\hline Primary balances & -0.08 & 0.07 & -1.81 & -2.89 & -3.54 & -4.42 & -4.70 \\
\hline Primary revenue & 37.67 & 37.91 & 37.91 & 37.91 & 37.91 & 37.91 & 37.91 \\
\hline Primary exp other than PE \& HE & 25.97 & 24.22 & 24.22 & 24.22 & 24.22 & 24.22 & 24.22 \\
\hline Old age pension spending(authors) $1 /$ & 3.90 & 4.73 & 5.58 & 6.09 & 6.42 & 6.86 & 7.02 \\
\hline Health spending(authors) & 7.88 & 8.90 & 9.93 & 10.50 & 10.81 & 11.24 & 11.37 \\
\hline $\begin{array}{l}\text { Health spending(Fiscal Sustainability } \\
\text { Report } 2018 \text { by PBO) } 2 /\end{array}$ & 7.5 & 7.6 & 8.1 & 8.9 & 9.3 & 9.3 & 9.5 \\
\hline \multicolumn{8}{|l|}{ Assumptions for pension projections } \\
\hline Coverage ratio (CPP \& QPP) & 1.09 & 1.09 & 1.09 & 1.09 & 1.09 & 1.09 & 1.09 \\
\hline Coverage ratio (OAS) & 0.95 & 0.95 & 0.95 & 0.95 & 0.95 & 0.95 & 0.95 \\
\hline Replacement ratio (CPP \& QPP) & 0.06 & 0.06 & 0.06 & 0.06 & 0.06 & 0.06 & 0.06 \\
\hline Replacement ratio (OAS) & 0.06 & 0.06 & 0.06 & 0.06 & 0.06 & 0.06 & 0.06 \\
\hline \multicolumn{8}{|l|}{ Assumptions for health projections } \\
\hline Acceleration factor for $\mathrm{HE} 65+$ & $-0.583 /$ & $1.005 /$ & 1.00 & 1.00 & 1.00 & 1.00 & 1.00 \\
\hline Acceleration factor for HE $0-64$ & $0.964 /$ & 0.96 & 0.96 & 0.96 & 0.96 & 0.96 & 0.96 \\
\hline
\end{tabular}

$1 /$ This includes retirement benefits of Canada and Quebec Pension Plans and Old Age Security proram but does not include other benetifs (e.g. disability, survivor) under these plans nad program.

2/ Based on a different model, taking into account nominal GDP growth and demographic changes, but not acceleration of per-person health spending growth (see Office of Parliamentary Budget Officer (2017)).

3 / Calculated as average annual growth rate of per-person health spending between 2016-18 divided by average annual growth rate of GDP per capita between 2010-18.

4/ Calculated as average annual growth rate of per-person health spending between 2010-18 divided by average annual growth rate of GDP per capita between 2010-18.

5/ Based on the 2011 announcement of the Canada Health Transfer system reform, per-person health spending for population above 65 years old is assumed to grow at the same rate as GDP per capita.

Pension and Health Reforms Taken into Account in the Projections

\begin{tabular}{|l|l|}
\hline \multicolumn{1}{|c|}{ Reforms } & \multicolumn{1}{|c|}{ Measures } \\
\hline Pension & - \\
\hline N/a & $\begin{array}{l}\text { After 2017-18, the amount of Canada Health Transfer to provinces will growth in } \\
\text { line with a three-year moving average of nominal GDP, with the minimum } \\
\text { increase by 3 percent per year. }\end{array}$ \\
\hline 2011 announcement
\end{tabular}




\section{Germany}

\begin{tabular}{|c|c|c|c|c|c|c|c|}
\hline & 2018 & 2024 & 2030 & 2040 & 2050 & 2060 & 2068 \\
\hline \multicolumn{8}{|l|}{ Demographic projections } \\
\hline Old-age dependency ratio $(65+/ 15-64)$ & 0.33 & 0.37 & 0.45 & 0.53 & 0.54 & 0.58 & 0.58 \\
\hline \multicolumn{8}{|l|}{ Macroeconomic assumptions } \\
\hline Real GDP growth rate & 1.52 & 1.17 & 1.10 & 1.39 & 1.30 & 1.33 & 1.46 \\
\hline Growth rate of labor & - & -0.78 & -0.90 & -0.35 & -0.52 & -0.47 & -0.20 \\
\hline Growth rate of hours worked & - & 0.54 & 0.54 & 0.54 & 0.54 & 0.54 & 0.54 \\
\hline Growth rate of capital stock & - & 1.61 & 1.61 & 1.61 & 1.61 & 1.61 & 1.61 \\
\hline Growth rate of total factor productivity & - & 0.52 & 0.52 & 0.52 & 0.52 & 0.52 & 0.52 \\
\hline Labor share & $\begin{array}{r}0.52 \\
(\text { Av. 2014-18) } \\
\end{array}$ & 0.52 & 0.52 & 0.52 & 0.52 & 0.52 & 0.52 \\
\hline Nominal GDP growth rate & 3.06 & 3.33 & 3.27 & 3.56 & 3.47 & 3.50 & 3.64 \\
\hline Deflator change rate & 1.52 & 2.14 & 2.14 & 2.14 & 2.14 & 2.14 & 2.14 \\
\hline \multicolumn{8}{|l|}{ Fiscal projections } \\
\hline Primary balances & 2.57 & 1.16 & -0.72 & -3.33 & -4.14 & -5.28 & -5.62 \\
\hline Primary revenue & 46.19 & 45.75 & 45.75 & 45.75 & 45.75 & 45.75 & 45.75 \\
\hline Primary exp other than PE \& HE & 26.86 & 26.78 & 26.78 & 26.78 & 26.78 & 26.78 & 26.78 \\
\hline Old age pension spending (authors) & 7.62 & 8.03 & 8.95 & 10.40 & 10.68 & 11.16 & 11.15 \\
\hline $\begin{array}{l}\text { Old age pension spending (Aging } \\
\text { Report 2018) }\end{array}$ & $\begin{array}{r}7.8 \\
(2016) \\
\end{array}$ & - & 9.4 & 10.1 & 10.3 & 10.7 & $\begin{array}{r}10.8 \\
(2070) \\
\end{array}$ \\
\hline Health spending(authors) & 9.14 & 9.77 & 10.74 & 11.89 & 12.43 & 13.09 & 13.44 \\
\hline $\begin{array}{l}\text { Health spending (Aging Report } 2018, \\
\text { non-demog./cost convergence scenario) }\end{array}$ & $\begin{array}{r}8.7 \\
(2016) \\
\end{array}$ & & 10.2 & 11.2 & 12.5 & 13.1 & $\begin{array}{r}13.6 \\
(2070) \\
\end{array}$ \\
\hline \multicolumn{8}{|l|}{ Assumptions for pension projections } \\
\hline Coverage ratio & 1.09 & 1.03 & 0.97 & 0.97 & 0.97 & 0.97 & 0.97 \\
\hline Replacement ratio & 0.16 & 0.16 & 0.16 & 0.16 & 0.16 & 0.16 & 0.16 \\
\hline \multicolumn{8}{|l|}{ Assumptions for health projections } \\
\hline Acceleration factor for HE $65+$ & $1.271 /$ & $1.063 /$ & 1.06 & 1.06 & 1.06 & 1.06 & 1.06 \\
\hline Acceleration factor for HE 0-64 & $1.152 /$ & 1.15 & 1.15 & 1.15 & 1.15 & 1.15 & 1.15 \\
\hline
\end{tabular}

$1 /$ Calculated as average annual growth rate of per-person health spending between 2016-18 divided by average annual growth rate of GDP per capita between 2010-18

2/ Calculated as average annual growth rate of per-person health spending between 2010-18 divided by average annual growth rate of GDP per capita between 2010-18

3/ This assumption takes into account the health projections of the Aging Report 2018

Pension and Health Reforms Taken into Account in the Projections

\begin{tabular}{|c|c|}
\hline Reforms & Measures \\
\hline \multicolumn{2}{|l|}{ Pension 4/ } \\
\hline 2004 reform & Introduction of a "sustainability factor" added to the pension benefit adjustment formula \\
\hline 2007 reform & $\begin{array}{l}\text { Gradual rise of retirement age from } 65 \text { to } 67 \text { by } 2030 \\
\text { Termination of early retirement before } 63 \text { years old in } 2011\end{array}$ \\
\hline \multicolumn{2}{|r|}{ ( } \\
\hline $\begin{array}{l}2007 \text { Health Insurance } \\
\text { Competition Enhancing Act }\end{array}$ & $\begin{array}{l}\text { Introduction of "cost-benefit assessment" to determine reimbursement prices for drugs by the } \\
\text { health insurance funds }\end{array}$ \\
\hline 2010 GVK Finance Act & $\begin{array}{l}\text { Rise of contribution rates to the health insurance funds, including the requirements of } \\
\text { additional contributions in case of health spending being higher than planned }\end{array}$ \\
\hline $\begin{array}{l}\text { 2011 Pharmaceutical Market } \\
\text { Reform Act }\end{array}$ & $\begin{array}{l}\text { Introduction of assessment of "added therapeutic benefit" of new medicines when } \\
\text { determining prices to be paid by the health insurance funds }\end{array}$ \\
\hline
\end{tabular}

$4 /$ In 2019, the pension reform measure introduced the "double thresholds" that set a maximum contribution rate at $20 \%$ and a minimum replacement rate at $48 \%$ until the end 2025 . This reform is not incorporated into the projections in this note, as it took effect in 2019. 


\begin{tabular}{|c|c|c|c|c|c|c|c|}
\hline & 2018 & 2024 & 2030 & 2040 & 2050 & 2060 & 2068 \\
\hline \multicolumn{8}{|l|}{ Demographic projections } \\
\hline Old-age dependency ratio $(65+/ 15-64)$ & 0.32 & 0.36 & 0.40 & 0.46 & 0.47 & 0.47 & 0.48 \\
\hline \multicolumn{8}{|l|}{ Macroeconomic assumptions } \\
\hline Real GDP growth rate & 1.72 & 1.43 & 1.44 & 1.49 & 1.51 & 1.51 & 1.48 \\
\hline Growth rate of labor & - & -0.11 & -0.10 & -0.01 & 0.05 & 0.03 & -0.02 \\
\hline Growth rate of hours worked & - & 0.27 & 0.27 & 0.27 & 0.27 & 0.27 & 0.27 \\
\hline Growth rate of capital stock & - & 1.57 & 1.57 & 1.57 & 1.57 & 1.57 & 1.57 \\
\hline Growth rate of total factor productivity & - & 0.60 & 0.60 & 0.60 & 0.60 & 0.60 & 0.60 \\
\hline Labor share & $\begin{array}{r}0.52 \\
(\text { Av. 2014-18) } \\
\end{array}$ & 0.52 & 0.52 & 0.52 & 0.52 & 0.52 & 0.52 \\
\hline Nominal GDP growth rate & 2.53 & 3.15 & 3.16 & 3.20 & 3.23 & 3.22 & 3.19 \\
\hline Deflator change rate & 0.79 & 1.69 & 1.69 & 1.69 & 1.69 & 1.69 & 1.69 \\
\hline \multicolumn{8}{|l|}{ Fiscal projections } \\
\hline Primary balances & -0.91 & -1.39 & -2.70 & -3.84 & -3.77 & -3.37 & -3.35 \\
\hline Primary revenue & 53.42 & 51.31 & 51.31 & 51.31 & 51.31 & 51.31 & 51.31 \\
\hline Primary exp other than PE \& HE & 32.76 & 29.92 & 29.92 & 29.92 & 29.92 & 29.92 & 29.92 \\
\hline Old age pension spending(authors) & 12.11 & 12.64 & 13.22 & 13.32 & 12.57 & 11.48 & 10.81 \\
\hline $\begin{array}{l}\text { Old age pension spending (COR June } \\
2019 \text { Report, } g=1.5 \% \text { scenario) }\end{array}$ & $13.81 /$ & 13.9 & 13.8 & 13.4 & 13.1 & 12.7 & 12.5 \\
\hline Health spending(authors) & 9.46 & 10.15 & 10.88 & 11.92 & 12.60 & 13.28 & 13.94 \\
\hline $\begin{array}{l}\text { Health spending (Aging Report } 2018, \\
\text { non-demog./cost convergence scenario) }\end{array}$ & $\begin{array}{r}9.6 \\
(2016) \\
\end{array}$ & & 10.9 & 12.2 & 13.3 & 14.3 & $\begin{array}{r}15 \\
(2070) \\
\end{array}$ \\
\hline \multicolumn{8}{|l|}{ Assumptions for pension projections } \\
\hline Coverage ratio & 1.27 & 1.24 & 1.22 & 1.17 & 1.17 & 1.17 & 1.17 \\
\hline Replacement ratio & 0.19 & 0.19 & 0.18 & 0.16 & 0.15 & 0.14 & 0.13 \\
\hline \multicolumn{8}{|l|}{ Assumptions for health projections } \\
\hline Acceleration factor for HE $65+$ & $0.212 /$ & $1.004 /$ & 1.00 & 1.00 & 1.00 & 1.00 & 1.00 \\
\hline Acceleration factor for HE $0-64$ & $2.883 /$ & $1.425 /$ & 1.42 & 1.42 & 1.42 & 1.42 & 1.42 \\
\hline
\end{tabular}

$1 /$ There is difference in the 2018 levels as COR Report projections capture some occupational schemes that are not captured by old-age pension figures of ESSPROS (Eurostat), on which this paper is based.

2/ Calculated as average annual growth rate of per-person health spending between 2016-18 divided by average annual growth rate of GDP per capita between 2010-18

3/ Calculated as average annual growth rate of per-person health spending between 2010-18 divided by average annual growth rate of GDP per capita between 2010-18

4 / In the absence of the long-term cost containment measures, per-person health spending for population above 65 years old is assumed to grow at the same rate as GDP per capita

5 / The acceleration factor for per-person health spending for population below 64 years old is assumed to be around half of the historical average in 2018 , to avoid explosive projections.

Pension and Health Reforms Taken into Account in the Projections

\begin{tabular}{|l|l|}
\hline \multicolumn{2}{|c|}{ Reforms } \\
\hline Pension & Gradual rise of retirement age from 65 to 67 \\
\hline 2010 reform & Gradual rise of a contribution period to 43 years until 2035 \\
\hline 2014 reform & Introduction of polypension rules applicable to individuals who join multiple schemes \\
\hline 2015 Agric-Arrco agreement & Introduction of "solidarity coefficients" and "increase coefficients" \\
\hline 2017 LURA reform & Introduction of ONDAM ceilings \\
\hline Health & Unification of pricing systems by public and private hospitals \\
\hline 1997 reform & $\begin{array}{l}\text { Introduction of cost contamination measures including limits to drug procurement and } \\
\text { adherence to ONDAM ceilings }\end{array}$ \\
\hline 2004 reform
\end{tabular}




\begin{tabular}{|c|c|c|c|c|c|c|c|}
\hline & 2018 & 2024 & 2030 & 2040 & 2050 & 2060 & 2068 \\
\hline \multicolumn{8}{|l|}{ Demographic projections } \\
\hline Old-age dependency ratio $(65+/ 15-64)$ & 0.37 & 0.41 & 0.48 & 0.63 & 0.66 & 0.63 & 0.60 \\
\hline \multicolumn{8}{|l|}{ Macroeconomic assumptions } \\
\hline Real GDP growth rate & 0.86 & 0.65 & 0.57 & 0.62 & 0.80 & 0.85 & 0.86 \\
\hline Growth rate of labor & - & -0.88 & -1.07 & -0.94 & -0.48 & -0.35 & -0.35 \\
\hline Growth rate of hours worked & - & 0.98 & 0.98 & 0.98 & 0.98 & 0.98 & 0.98 \\
\hline Growth rate of capital stock & - & 1.14 & 1.14 & 1.14 & 1.14 & 1.14 & 1.14 \\
\hline Growth rate of total factor productivity & - & -0.08 & -0.08 & -0.08 & -0.08 & -0.08 & -0.08 \\
\hline Labor share & $\begin{array}{r}0.39 \\
(\text { Av. 2014-18) } \\
\end{array}$ & 0.39 & 0.39 & 0.39 & 0.39 & 0.39 & 0.39 \\
\hline Nominal GDP growth rate & 1.71 & 2.15 & 2.08 & 2.13 & 2.31 & 2.37 & 2.37 \\
\hline Deflator change rate & 0.85 & 1.50 & 1.50 & 1.50 & 1.50 & 1.50 & 1.50 \\
\hline \multicolumn{8}{|l|}{ Fiscal projections } \\
\hline Primary balances & 1.39 & 0.19 & -1.76 & -4.98 & -4.72 & -2.85 & -2.15 \\
\hline Primary revenue & 46.28 & 46.42 & 46.42 & 46.42 & 46.42 & 46.42 & 46.42 \\
\hline Primary exp other than PE \& HE & 25.21 & 25.28 & 25.28 & 25.28 & 25.28 & 25.28 & 25.28 \\
\hline Old age pension spending(authors) & 13.14 & 13.92 & 15.14 & 17.14 & 16.14 & 13.74 & 12.58 \\
\hline $\begin{array}{l}\text { Old age pension spending (Aging } \\
\text { Report 2018) }\end{array}$ & $\begin{array}{r}12.7 \\
(2016) \\
\end{array}$ & & 14.2 & 15.6 & 14.4 & 12.6 & $\begin{array}{r}11.8 \\
(2070) \\
\end{array}$ \\
\hline Health spending(authors) & 6.53 & 7.03 & 7.75 & 8.98 & 9.72 & 10.24 & 10.71 \\
\hline $\begin{array}{l}\text { Health spending (Aging Report } 2018, \\
\text { non-demog./cost convergence scenario) }\end{array}$ & $\begin{array}{r}8.01 / \\
(2016) \\
\end{array}$ & & 9.0 & 10.1 & 11.3 & 12.2 & $\begin{array}{r}12.4 \\
(2070) \\
\end{array}$ \\
\hline \multicolumn{8}{|l|}{ Assumptions for pension projections } \\
\hline Coverage ratio & 0.90 & 0.86 & 0.81 & 0.77 & 0.76 & 0.75 & 0.73 \\
\hline Replacement ratio & 0.25 & 0.24 & 0.24 & 0.22 & 0.20 & 0.18 & 0.18 \\
\hline \multicolumn{8}{|l|}{ Assumptions for health projections } \\
\hline Acceleration factor for HE $65+$ & $\begin{array}{l}1.142 / \\
(2010) \\
\end{array}$ & $1.144 /$ & 1.14 & 1.14 & 1.14 & 1.14 & 1.14 \\
\hline Acceleration factor for HE $0-64$ & $\begin{array}{l}1.613 / \\
(2010) \\
\end{array}$ & $1.504 /$ & 1.50 & 1.50 & 1.50 & 1.50 & 1.50 \\
\hline
\end{tabular}

$1 /$ There is difference in the 2016/18 levels, because the Aging Report is based on System of Health Accounts standards, which include broader items (such as long-term care by family at home) than ESSPROS (Eurostat), on which this paper is based.

2/ Calculated as average of acceleration factors between 2005 and 2010, which are calculated as average annual growth rate of per-person health spending for three years divided by average annual growth rate of GDP per capita for eight years. 3/ Calculated as average annual growth rate of per-person health spending between 2007-10 divided by average annual growth rate of GDP per capita between 2002-10

4/ In recent years, acceleration factors have been at low levels because of the Deficit Reduction Plans applied to the regional budgets. Because the Deficit Reduction Plans are limited to the medium-term horizon, we take into account the levels of acceleration factors before 2010 when the Deficit Reduction Plans were expanded to several regions.

Pension and Health Reforms Taken into Account in the Projections

\begin{tabular}{|l|l|}
\hline \multicolumn{1}{|c|}{ Reforms } & \multicolumn{1}{|c|}{ Measures } \\
\hline Pension & The gradual shift from the Defined Benefit scheme to the National Defined Contribution scheme \\
\hline 1995 reform & $\begin{array}{l}\text { The introduction of a “trans formation coefficient", based on mortality rates and life expectancy, to } \\
\text { the pension benefit formula under the National Defined Contribution scheme. }\end{array}$ \\
\hline 2007 reform & Indexation of the eligibility age to changes in life expectancy \\
\hline 2010 reform & $\begin{array}{l}\text { Increase in retirement ages from 65 (men)/60 (women) to 66 (men)/63 (women) for the Defined } \\
\text { Benefit scheme and from 65(men)/60 (women) to 70 for the National Defined Contribution scheme. }\end{array}$ \\
\hline 2011 reform & $\begin{array}{l}\text { The requirements of regions' "Deficit Reduction plans", which set out plans for reduction of } \\
\text { deficits of regional budgets. }\end{array}$ \\
\hline Health & $\begin{array}{l}\text { Introduction of standard costing and benchmarking criteria in determining allocation of health } \\
\text { financial resources to regions }\end{array}$ \\
\hline $\begin{array}{l}\text { 2007 Finance Law } \\
\text { and onward }\end{array}$ &
\end{tabular}




\begin{tabular}{|c|c|c|c|c|c|c|c|}
\hline & 2018 & 2024 & 2030 & 2040 & 2050 & 2060 & 2068 \\
\hline \multicolumn{8}{|l|}{ Demographic projections } \\
\hline Old-age dependency ratio $(65+/ 15-64)$ & 0.46 & 0.50 & 0.53 & 0.64 & 0.71 & 0.72 & 0.70 \\
\hline \multicolumn{8}{|l|}{ Macroeconomic assumptions } \\
\hline Real GDP growth rate & 0.81 & 0.50 & 0.44 & 0.26 & 0.38 & 0.49 & 0.53 \\
\hline Growth rate of labor & - & -0.62 & -0.74 & -1.10 & -0.86 & -0.65 & -0.57 \\
\hline Growth rate of hours worked & - & 0.55 & 0.55 & 0.55 & 0.55 & 0.55 & 0.55 \\
\hline Growth rate of capital stock & - & 0.49 & 0.49 & 0.49 & 0.49 & 0.49 & 0.49 \\
\hline Growth rate of total factor productivity & - & 0.30 & 0.30 & 0.30 & 0.30 & 0.30 & 0.30 \\
\hline Labor share & $\begin{array}{r}0.51 \\
(\text { Av. 2014-18) } \\
\end{array}$ & 0.51 & 0.51 & 0.51 & 0.51 & 0.51 & 0.51 \\
\hline Nominal GDP growth rate & 0.71 & 1.37 & 1.31 & 1.13 & 1.25 & 1.36 & 1.40 \\
\hline Deflator change rate & -0.10 & 0.87 & 0.87 & 0.87 & 0.87 & 0.87 & 0.87 \\
\hline \multicolumn{8}{|l|}{ Fiscal projections } \\
\hline Primary balances & -2.92 & -2.00 & -2.19 & -4.88 & -7.55 & -9.52 & -10.76 \\
\hline Primary revenue & 32.45 & 33.32 & 33.32 & 33.32 & 33.32 & 33.32 & 33.32 \\
\hline Primary exp other than PE \& HE & 17.49 & 17.08 & 17.08 & 17.08 & 17.08 & 17.08 & 17.08 \\
\hline Old age pension spending (authors) & 9.69 & 9.27 & 8.61 & 9.27 & 9.97 & 10.12 & 9.90 \\
\hline $\begin{array}{l}\text { Old age pension spending(Actuarial } \\
\text { Estimate } 2019 \text { by MoHLW, Case III) }\end{array}$ & $\begin{array}{r}9.5 \\
(2019) \\
\end{array}$ & & 8.4 & 8.6 & & 9.5 & \\
\hline Health spending(authors) & 8.19 & 8.97 & 9.82 & 11.86 & 13.81 & 15.63 & 17.10 \\
\hline $\begin{array}{l}\text { Health spending (2018 Social Security } \\
\text { Outlook for } 2040 \text { by Cabinet Office) }\end{array}$ & 8.8 & $\begin{array}{r}9.8 \\
(2025) \\
\end{array}$ & & 12.0 & & - & \\
\hline \multicolumn{8}{|l|}{ Assumptions for pension projections } \\
\hline Coverage ratio & 1.42 & 1.31 & 1.21 & 1.21 & 1.21 & 1.21 & 1.21 \\
\hline Replacement ratio & 0.13 & 0.12 & 0.12 & 0.11 & 0.11 & 0.11 & 0.11 \\
\hline \multicolumn{8}{|l|}{ Assumptions for health projections } \\
\hline Acceleration factor for HE $65+$ & $0.221 /$ & $1.733 /$ & 1.73 & 1.73 & 1.73 & 1.73 & 1.73 \\
\hline Acceleration factor for HE $0-64$ & $1.202 /$ & 1.20 & 1.20 & 1.20 & 1.20 & 1.20 & 1.20 \\
\hline
\end{tabular}

1/ Calculated as average annual growth rate of per-person health spending between 2016-18 divided by average annual growth rate of GDP per capita between 2010-18

2/ Calculated as average annual growth rate of per-person health spending between 2010-18 divided by average annual growth rate of GDP per capita between 2010-18

3 / Taking into account the assumptions of health care unit prices in the 2018 Social Security Outlook, this is calculated by the following equation: $\alpha=\left(g_{2068} \times 0.3+2 \%\right) / g_{2068}$ where $g_{t}$ is nominal growth rate at time $t$.

Pension and Health Reforms Taken into Account in the Projections

\begin{tabular}{|l|l|}
\hline \multicolumn{1}{|c|}{ Reforms } & \multicolumn{1}{|c|}{ Measures } \\
\hline Pension & \multicolumn{2}{|c|}{} \\
\hline 2000 reform & Gradual rise of a retirement age from 60 to 65 until 2025 for men and 2030 for women \\
\hline 2004 reform & Introduction of "macro-economic slide" adjustments to pension benefits \\
\hline Health & \multicolumn{2}{|c|}{ Introduction of the long-term care insurance } \\
\hline 2000 reform & Adjustments to coverage of the long-term care insurance \\
\hline 2005 reform & Introduction of the late-elderly care scheme and a gradual increase in co-payment by late-elderly persons \\
\hline $\begin{array}{l}2008 \text { reform } \\
\text { reforms }\end{array}$ & An increase in co-payment by high-income persons for long-term care insurance \\
\hline
\end{tabular}




\section{UK}

\begin{tabular}{|c|c|c|c|c|c|c|c|}
\hline & 2018 & 2024 & 2030 & 2040 & 2050 & 2060 & 2068 \\
\hline \multicolumn{8}{|l|}{ Demographic projections } \\
\hline Old-age dependency ratio $(65+/ 15-64)$ & 0.29 & 0.32 & 0.36 & 0.41 & 0.44 & 0.47 & 0.47 \\
\hline \multicolumn{8}{|l|}{ Macroeconomic assumptions } \\
\hline Real GDP growth rate & 1.40 & 1.53 & 1.55 & 1.58 & 1.50 & 1.54 & 1.57 \\
\hline Growth rate of labor & - & 0.08 & 0.12 & 0.19 & 0.03 & 0.09 & 0.17 \\
\hline Growth rate of hours worked & - & 0.40 & 0.40 & 0.40 & 0.40 & 0.40 & 0.40 \\
\hline Growth rate of capital stock & - & 2.47 & 2.47 & 2.47 & 2.47 & 2.47 & 2.47 \\
\hline Growth rate of total factor productivity & - & 0.03 & 0.03 & 0.03 & 0.03 & 0.03 & 0.03 \\
\hline Labor share & 0.49 & 0.49 & 0.49 & 0.49 & 0.49 & 0.49 & 0.49 \\
\hline Nominal GDP growth rate & 3.32 & 3.55 & 3.57 & 3.60 & 3.52 & 3.56 & 3.59 \\
\hline Deflator change rate & 1.90 & 1.99 & 1.99 & 1.99 & 1.99 & 1.99 & 1.99 \\
\hline \multicolumn{8}{|l|}{ Fiscal projections } \\
\hline Primary balances & 0.15 & 0.05 & -1.43 & -3.58 & -5.59 & -7.86 & -9.28 \\
\hline Primary revenue & 36.00 & \begin{tabular}{l|l}
36.22 \\
\end{tabular} & 36.22 & \begin{tabular}{l|l}
36.22 \\
\end{tabular} & 36.22 & 36.22 & 36.22 \\
\hline Primary exp other than PE \& HE & 23.80 & 22.97 & 22.97 & 22.97 & 22.97 & 22.97 & 22.97 \\
\hline Old age pension spending(authors) & 4.43 & 4.65 & 5.00 & 5.45 & 5.95 & 6.46 & 6.60 \\
\hline $\begin{array}{l}\text { Old age pension spending(Aging } \\
\text { Report 2018) }\end{array}$ & $\begin{array}{r}4.9 \\
(2016) \\
\end{array}$ & & \begin{tabular}{ll|}
5.4 \\
\end{tabular} & 6.1 & 6.0 & 6.5 & $\begin{array}{r}7.0 \\
(2017) \\
\end{array}$ \\
\hline Health spending(authors) & 7.62 & 8.55 & 9.67 & 11.38 & 12.89 & 14.65 & 15.93 \\
\hline $\begin{array}{l}\text { Health spending(Fiscal Sustainability } \\
\text { Report } 2018 \text { by OBR) }\end{array}$ & 7.1 & 7.7 & 8.7 & 10.2 & 11.6 & 12.9 & 13.8 \\
\hline \multicolumn{8}{|l|}{ Assumptions for pension projections } \\
\hline Coverage ratio & 1.03 & 0.98 & 0.92 & 0.87 & 0.87 & 0.87 & 0.87 \\
\hline Replacement ratio & 0.12 & \begin{tabular}{l|l}
0.12 \\
\end{tabular} & 0.12 & \begin{tabular}{l|l}
0.12 \\
\end{tabular} & 0.12 & \begin{tabular}{l|l}
0.13 \\
\end{tabular} & 0.13 \\
\hline \multicolumn{8}{|l|}{ Assumptions for health projections } \\
\hline Acceleration factor for HE $65+$ & $0.661 /$ & $1.203 /$ & 1.20 & 1.20 & 1.20 & 1.20 & 1.20 \\
\hline Acceleration factor for HE $0-64$ & $0.842 /$ & $1.623 /$ & 1.62 & \begin{tabular}{l|l}
1.62 \\
\end{tabular} & 1.62 & 1.62 & 1.62 \\
\hline
\end{tabular}

$1 /$ Calculated as average annual growth rate of per-person health spending between 2016-18 divided by average annual growth rate of GDP per capita between 2010-18

2/ Calculated as average annual growth rate of per-person health spending between 2010-18 divided by average annual growth rate of GDP per capita between 2010-18

3/ This takes into the effects of the June 2018 Announcement. Until 2023, total health spending is assumed to follow the nominal growth rates projected in the OBR 2019 Fiscal Risks Report (Table 5.4, the funding announcement scenario). After 2024, we hold the acceleration factors constant at the 2023 level.

Pension and Health Reforms Taken into Account in the Projections

\begin{tabular}{|c|c|}
\hline Reforms & Measures \\
\hline \multicolumn{2}{|l|}{ Pension } \\
\hline 2011 reform & $\begin{array}{l}\text { Introduction of "Triple Lock" to increase the new State Pension by the highest of average } \\
\text { earnings, CPI, or } 2.5 \text { percent }\end{array}$ \\
\hline 2014 Pension Act & $\begin{array}{l}\text { An increase of retirement age to } 67 \text { years old between } 2026 \text { and } 28 \text { and to } 68 \text { years old } \\
\text { between } 2044 \text { and } 46 .\end{array}$ \\
\hline 2016 reform & $\begin{array}{l}\text { Replacement of the previous two-tier State Pension system with the single tier new State } \\
\text { Pension system. }\end{array}$ \\
\hline 2017 State Pension age review & An increase of retirement age to 68 years old was brought forward to $2037-39$ \\
\hline \multicolumn{2}{|c|}{ Health } \\
\hline June 2018 Announcement & $\begin{array}{l}\text { In June } 2018 \text {, the PM announced to rise NHS England resource spending by } 3.4 \text { percent } \\
\text { per year in real terms from } 2018-19 \text { to } 2023-24 \text {. }\end{array}$ \\
\hline
\end{tabular}


$\mathbf{U S}$

\begin{tabular}{|c|c|c|c|c|c|c|c|}
\hline & 2018 & 2024 & 2030 & 2040 & 2050 & 2060 & 2068 \\
\hline \multicolumn{8}{|l|}{ Demographic projections } \\
\hline Old-age dependency ratio $(65+/ 15-64)$ & 0.24 & 0.29 & 0.33 & 0.36 & 0.36 & 0.40 & 0.42 \\
\hline \multicolumn{8}{|l|}{ Macroeconomic assumptions } \\
\hline Real GDP growth rate & 2.93 & 1.62 & 1.59 & 1.64 & 1.59 & 1.51 & 1.51 \\
\hline Growth rate of labor & - & 0.40 & 0.34 & 0.43 & 0.35 & 0.19 & 0.19 \\
\hline Growth rate of hours worked & - & -0.09 & -0.09 & -0.09 & -0.09 & -0.09 & -0.09 \\
\hline Growth rate of capital stock & - & 1.82 & 1.82 & 1.82 & 1.82 & 1.82 & 1.82 \\
\hline Growth rate of total factor productivity & - & 0.60 & 0.60 & 0.60 & 0.60 & 0.60 & 0.60 \\
\hline Labor share & 0.53 & 0.53 & 0.53 & 0.53 & 0.53 & 0.53 & 0.53 \\
\hline Nominal GDP growth rate & 5.43 & 3.67 & 3.64 & 3.68 & 3.64 & 3.55 & 3.55 \\
\hline Deflator change rate & 2.44 & 2.01 & 2.01 & 2.01 & 2.01 & 2.01 & 2.01 \\
\hline \multicolumn{8}{|l|}{ Fiscal projections } \\
\hline Primary balances & -3.54 & -2.91 & -4.91 & -6.44 & -7.68 & -9.65 & -11.30 \\
\hline Primary revenue & 28.95 & 31.15 & 31.15 & 31.15 & 31.15 & 31.15 & 31.15 \\
\hline Primary exp other than PE \& HE & 20.83 & 20.03 & 20.03 & 20.03 & 20.03 & 20.03 & 20.03 \\
\hline Old age pension spending(authors) & 4.11 & 5.11 & 5.79 & 6.24 & 6.39 & 6.92 & 7.34 \\
\hline $\begin{array}{l}\text { "Social Security" spending ( } 2019 \\
\text { Long-Term Budget Outlook by CBO) }\end{array}$ & 4.9 & & 5.9 & & 6.2 & - & \\
\hline Health spending(authors) & 7.55 & 8.94 & 10.25 & 11.33 & 12.42 & 13.86 & 15.09 \\
\hline $\begin{array}{l}\text { "Major Health Care Program" ( } 2019 \\
\text { Long-Term Budget Outlook by CBO) }\end{array}$ & $5.21 /$ & & 6.7 & & 9.3 & - & \\
\hline \multicolumn{8}{|l|}{ Assumptions for pension projections } \\
\hline Coverage ratio & 1.02 & 1.02 & 1.02 & 1.02 & 1.02 & 1.02 & 1.02 \\
\hline Replacement ratio & 0.13 & 0.13 & 0.13 & 0.13 & 0.13 & 0.13 & 0.13 \\
\hline \multicolumn{8}{|l|}{ Assumptions for health projections } \\
\hline Acceleration factor for HE $65+$ & $0.432 /$ & $1.784 /$ & 1.00 & 1.00 & 1.00 & 1.00 & 1.00 \\
\hline Acceleration factor for HE $0-64$ & $1.563 /$ & 1.56 & 1.56 & 1.56 & 1.56 & 1.56 & 1.56 \\
\hline
\end{tabular}

$1 /$ There is difference in the 2018 level, because the CBO projections capture only the federal government spending, while authors capture health spending by the state and local governments as well.

2/ Calculated as average annual growth rate of per-person health spending between 2016-18 divided by average annual growth rate of GDP per capita between 2010-18

3/ Calculated as average annual growth rate of per-person health spending between 2010-18 divided by average annual growth rate of GDP per capita between 2010-18

4 / We assume that per-person health spending for population above 65 years old will follow the average nominal annual growth rates projected in the 2019 Medicare Annual Report (5.13 percent per year). After 2029, we assume that per person health spending for population above 65 years old will follow the growth rates of GDP per capita (i.e. no acceleration).

Pension and Health Reforms Taken into Account in the Projections

\begin{tabular}{|l|l|}
\hline \multicolumn{1}{|c|}{ Reforms } & \multicolumn{1}{|c|}{ Measures } \\
\hline Pension N/a & \\
\hline \multicolumn{1}{|c|}{ Health } & $\begin{array}{l}\text { Introduction of a health insurance coverage option for persons that have been without health } \\
\text { coverage or have a pre-existing condition } \\
\text { Introduction of cost-reduction provisions for Medicare }\end{array}$ \\
\hline 2010 Affordable Care Act & Introduction of additional cost-reduction provisions for Medicare \\
\hline $\begin{array}{l}\text { 2015 Medicare Access and } \\
\text { CHIP Reauthorization Act }\end{array}$ & \\
\hline
\end{tabular}




\section{APPENDIX III. SENSITIVITY OF INFW TO INTEREST RATE CHANGES}

\section{The sensitivity of INFW to interest rates can be measured by duration and} convexity. As mentioned above, all seven countries have negative future costs of fiscal policy. This means that increase in interest rates will reduce the liabilities in the intertemporal PSBS. Drawing from the models for pension liabilities,${ }^{36}$ effective durations are used to express the sensitivity of INFW to interest rate changes:

$$
\text { Effective Duration }=\frac{L_{\delta-\Delta \delta}-L_{\delta+\Delta \delta}}{2 L_{r} \Delta \delta}
$$

where $L_{\delta}$ is INFW with discount rates $\delta$; and $\Delta \delta$ is the change in discount rate. The sensitivity of effective durations to changes in interest rates can be measured by effective convexities, which are the second derivative of changes in INFW to changes in discount rates:

$$
\text { Effective Convexity }=\frac{L_{\delta-\Delta \delta}+L_{\delta+\Delta \delta}-2 L_{\delta}}{2 L_{\delta}(\Delta \delta)^{2}}
$$

Figure 29. Durations of INFW

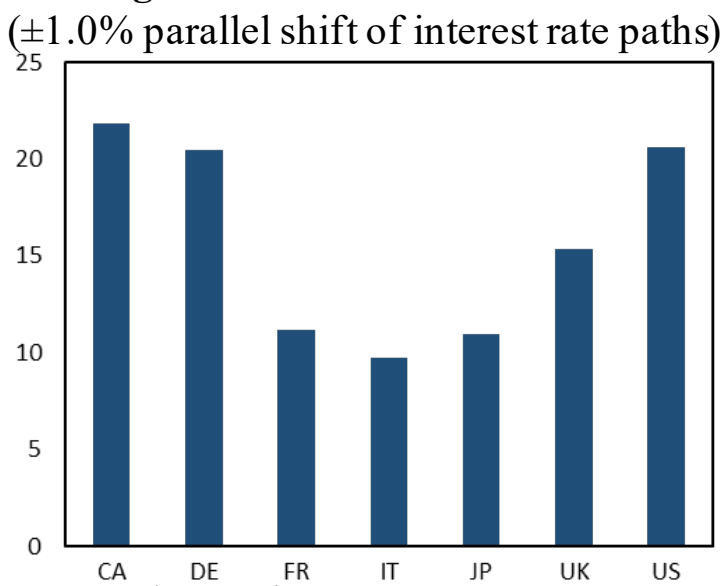

Source: Authors' estimates
Figure 30. Convexity of INFW $( \pm 1.0 \%$ parallel shift of interest rate paths)

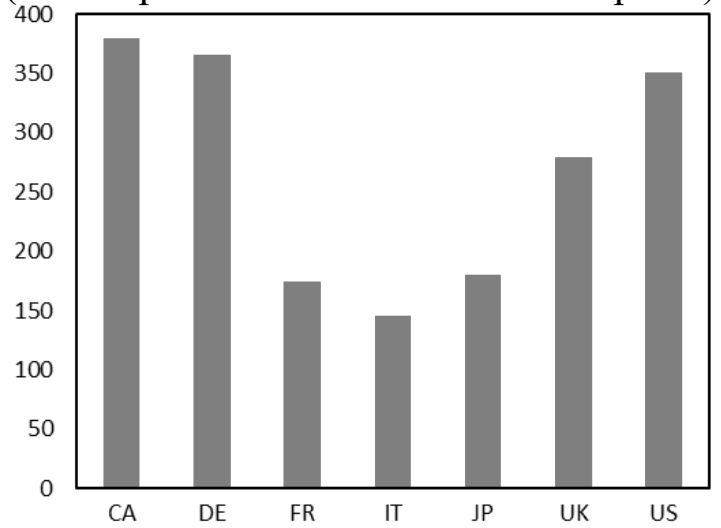

Source: Authors' estimates

58. The sensitivity of INFW to interest rate changes depends on its composition and the exact shape of the path of future primary deficits. For Japan, Italy, and France, INFW has shorter durations than other countries, because static NFW comprises more than half of their INFW (Figure 29). ${ }^{37}$ The duration of intertemporal liabilities also increases as large primary deficits shift further in to the future. For example, as UK is projected to accumulate larger primary deficits further into the future, the duration of its INFW is longer than Japan, Italy, and France, although for UK, static NFW also comprises more than half of INFW. The convexity of INFW follows the same trend (Figure 30). ${ }^{38}$

\footnotetext{
${ }^{36}$ McCaulay (2013).

${ }^{37}$ Avera ge durations of INFW for \pm 1 percent changes in interest rates are 16 , which is a t a similar level to dura tions of pension lia bilities measured by Chandler (2017), ra nging from 14 to 20 .

${ }^{38}$ Avera ge convexity of INFW for \pm 1 percent changes in interest rates a re 268 , la rger than convexity of certain bonds reported by Shiller et. a l. (2014), ranging from 0.7 to 218 .
} 


\section{APPENDIX IV. METHODS FOR ESTIMATING INTERTEMPORAL NET WORTH}

59. We estimate INW by incorporating impact of capital investments in future years on the stock of nonfinancial produced assets. In this model, the accounting identify of changes in stock of fixed assets, which comprise the largest part of nonfinancial produced assets of public sector, can be expressed as net investments (i.e. difference between gross fixed capital formation $\left(G F C F_{t}\right)$ and consumption of fixed assets $\left.\left(C_{t}\right)\right)$ plus revaluation gains $\left(\delta_{t} A_{t-1}\right)$ as follows:

$$
A_{t}-A_{t-1}=G F C F_{t}-C_{t}+\delta_{t} A_{t-1}
$$

When we scale this by nominal GDP and solve it in a similar manner as discussed in paragraph 8 , we obtain the following equation similar to the equation (1):

$$
\frac{A_{t}}{Y_{t}}=\sum_{j=1}^{\infty} d_{j}^{\prime} \frac{G F C F_{t+j}-C_{t+j}}{Y_{t+j}}
$$

where the discount factor $\mathrm{d}_{j}^{\prime}=\prod_{k=1}^{j} \frac{1+g_{t+k}}{1+\delta_{t+k}}$. In this equation, we assume that the stock of nonfinancial produced assets at an infinite point in the future is fully depreciated away (i.e. $\lim _{T \rightarrow \infty} \prod_{j=1}^{T} d^{\prime}{ }_{T} \frac{A_{T}}{Y_{Y}}=0$ ). By adding the right hand side of the equation (7) to the equation (2) and replacing NFW with NW, we obtain the following equation for INW:

$$
\mathrm{INW}_{t}=N W_{t}+\sum_{j=1}^{T} \frac{R_{t+j}-G_{t+j}}{(1+r)^{j}}+\sum_{j=1}^{\infty} d_{j}^{\prime} \frac{G F C F_{t+j}-C_{t+j}}{Y_{t+j}}
$$

60. Revaluation gains are assumed to follow price changes as per common statistical practices. EUROSTAT (2013) recommends that revaluation gains be decomposed into neutral holding gains reflecting changes in price levels and real holding gains reflecting changes beyond the price changes. The UK Office for National Statistics (2019) uses GDP deflators for computing neutral holding gains of public capital stock. The Japan Cabinet Office (2017) calculates real holding gains of infrastructure assets (e.g. roads, water pipes, etc.) as residuals to accommodate descrepancies in various data sources. Drawing from these statistical practices, we assume that revaluation rates of nonfinancial produced assets $\left(\delta_{t}\right)$ follow GDP deflators. Revaluation gains/losses of non-produced assets recorded in the national account statistics seem very volatile. For example, annual rates of other economic flows (i.e. revaluation gains plus discovery of assets) of natural resources in Canada swang in a year from -97.8 percent (in 1990) to +68.6 percent (in 1991). Revaluation rates of lands also tend to flactuate significantly from one year to another. Therefore, we assume that mean of revaluation rates of non-produced assets are zero in a long-run.

\section{The life of infrastructure assets will be shortened without sufficient capital}

repairs. The consumption of fixed capital is calculated as the average stock of nonfinancial produced assets during a year times depreciation rates. When estimating depreciation rates, we take into account a relationship between adequacy of capital repairs and life of assets. In 
case of roads, Wilde et. al. (2014) cites a pavement maintenance strategy of a municipality in US, which shows that the life of asphalt pavement will be shortened from around 60 years to 30 years when only recurrent maintenance is undertaken and no capital repair is made after the initial investment. Zhang et. al. (2017) also shows that the life of some bridge deck can be shortened from 53 years to 35 years without capital repairs. To prevent reduction of the life of road sections, Trigaux et. al. (2016) shows that maintenance with the amount of around 67 percent of initial investments in real terms has to be made during the life-time.

\section{In this paper, a depreciation rate of produced nonfinancial assets is estimated by} a model depending on sufficiency of capital maintenance during the life time. Borrowing from the studies noted above, we assume that the life of produced nonfinancial assets will be shortened by up to 50 percent, in proportion to an cumulative shortage in required capital maintenance. The amount of capital maitenance required for keepting the life of assets is assumed to be 50 percent of initial investments in real time, spread across the life-time. Under these assumptions, a depreciation rate of nonfinancial assets produced at time $T$ is based on the following equations:

$$
\begin{gathered}
d_{t, T}=\frac{1}{N_{t, T}} \\
N_{t, T}=\max \left(50 \% \times \frac{1}{c}, \frac{1}{c} \times\left(1-\sum_{k}^{j} \frac{\theta_{t, t+k}-I_{t, t+k}}{\theta_{t, t+k} \times \frac{1}{c}}\right)\right)
\end{gathered}
$$

where $d_{t, T}$ is a depreciation rate at time $T$ of assets produced at time $t, N_{t, T}$ is life of assets produced at time $t$ as of time $T$ in terms of number of years, c is constant showing a historical average of depreciaration rates, derived from the national account statistics of respective countries, $\theta_{t, T}$ is amount of minimum required investment at time $T$ for assets produced at time $t, I_{t, T}$ is amount of actual investment made at time $T$ for assets produced at time $t . \theta_{t, T}>$ $I_{t, T}$. Amount of minimum required investment is based on the following equation:

$$
\theta_{t, T}=V_{t} \times 50 \% \times c \times \prod_{k=1}^{j} 1+\sigma_{t+k}
$$

where $V_{t}$ is amount of initial investment made for assets produced at time $t, \sigma_{T}$ is GDP deflator at time $T$. The stock of produced assets in Year 0 (2018) are assumed to be all produced in Year 0 with $\mathrm{V}_{0}=$ the amount of the stock in Year 0 . Allocation of capital expenditure is assumed to prioritize minimum required investment of assets built in an earlier year over that of assets built in a later year. Under this assumption, amount of actual investmnet follows that: 


$$
\mathrm{I}_{t, T}=\max \left(0, G F C F_{T}-\sum_{k=0}^{t^{\prime}} \theta_{k, T}\right)
$$

where $\mathrm{t}^{\prime}<\mathrm{t} . G F C F_{T}$ is total gross fixed capital formation at time $T$. If there is remainder in capital expenditure after meeting all minimum required investments of assets built in previous years, the remaining amount is assumed to be used to produce new assets. 


\section{REFERENCES}

Afonso, Antonio, and Manuel M.F. Martins, 2010, "Level, Slope, Curvature of The Sovereign Yield Curve, and Fiscal Behaviro”, European Central Bank Working Paper Series No. 1276/December 2010

Allen, M., C. Rosenberg, C. Keller, B. Setser, and N. Roubini. 2002. "A Balance Sheet Approach to Financial Crises.” IMF Working Paper 02/210, International Monetary Fund, Washington, DC.

Alves, Miguel, Sage De Clerck, and Juliana Gamboa-Arbelaez, 2020, "Public Sector Balance Sheet Database: Overview and Guide for Compilers and Users", IMF Working Paper WP/20/130, (Washington: International Monetary Fund)

Amaglobeli, David, and Wei Shi, 2016, "How to Assess Fiscal Implications of Demographic Shifts: a Granular Approach”, IMF Fiscal Affairs Department How to Note No. 2/2016 (Washington: International Monetary Fund).

Barret, Philip, 2018, "Interest-Growth Differentials and Debt Limits in Advanced Economies”, IMF Working Paper WP/18/82, (Washington: International Monetary Fund).

Bauer, Michael D., Glenn D. Rudebusch, and Jing Cynthia Wu, 2014, “Term Premia and Inflation Uncertanty: Empirical Evidence from an International Panel Dataset: Comment", American Economic Review, 104(1), pp.323-337.

Beck, Nathaniel and Jonathan Katz, 1995, "What to Do (And Not to Do) with Time-Series Cross-Section Data", American Political Sciense Review, 89(3) pp.634-647

Bohn, Henning, 1998, "The Behavior of U.S. Public Debt and Deficits", The Quarterly Journal of Economics, 113(3), pp.949-963.

Bova, E., R. Dippelsman, K. Rideout, and A. Schaechter. 2013. “Another Look at Government's Balance Sheets: The Role of Nonfinancial Assets." IMF Working Paper 13/95, International Monetary Fund, Washington, DC.

Brede, Maren and Christian Henn, 2018, "Finland's Public Sector Balance Sheet: A Novel Approach to Analysis of Public Finance", IMF Working Paper WP/18/78 (Washington: International Monetary Fund).

Brede, Maren and Christian Henn, 2019, "Finland's Public Sector Balance Sheet", Baltic Journal of Economics, 19(1), pp.176-194.

Buiter, W. H. 1983. "Measurement of the Public-Sector Deficit and Its Implications for Policy Evaluation and Design.” IMF Staff Papers 30 (2): 306-49

Cabinet Office, 2017, Explanatory Notes on Estimation Methods for National Accouts (Annual Estimation), Cabinet Office: Tokyo, Japan 
Cabezon, Ezequiel and Christian Henn, 2018, "Counting the Oild Money and the Elderly: Norway's Public Sector Balance Sheet”, IMF Working Paper WP/18/190 (Washington: International Monetary Fund).

Cabezon, Ezequiel and Christian Henn, 2019, "Norway's Public Sector Balance Sheet", Applied Economics Letters, published online.

Caceres, Carlos, Yan Carriere-Swallow, Ishak Demir, and Bertrand Gruss, 2016, "U.S. Monetary Policy Normalization and Global Interest Rates”, IMF Working Paper WP/16/195 (Washington: International Monetary Fund).

Canadian Institute for Health Information, 2017, National Health Expenditure Trends 2020, Canadian Institute for Health Information: Ottawa, Canada.

Chalk, Nigel, and Richard Hemming, 2000, "Assessing Fiscal Sustainability in Theory and Practice", IMF Working Paper WP/00/81 (Washington: International Monetary Fund).

Chander, Doug, 2017, "Discount Rate Sensitivities in Pension Plans”, Society of Actuaries Studies No. 217034

Congressional Budget Office, 2019, The 2019 Long-Term Budget Outlook, Congressional Budget Office: Washington, D.C.

Crawford, Rowena, Paul Johnson, and Ben Zaranko, 2018, "The Planning and Control of UK Public Expenditure, 1993-2015”, Institute for Fiscal Studies, London, United Kingdom.

Crowder, William J., 1997, “The U.S. Federal Intertemporal Budget Constraint: Restoring Equilibrium Through Increased Revenues or Decreased Spending?”, University of Texas: Arlington, Texas.

Debrun, Xavier, Jonathan D. Ostry, Tim Willems, and Charles Wyplosz, 2018, "Public Debt Sustainability", Sovereign Debt: A Guide for Economists and Practitioners, Chapter 4 (Washinton: International Monetary Fund).

The Economist, 2020, "What would Keynes do? The pandemic will leave the rich world deep in debt, and force some hard choices", April 23.

El Rayess, Majdeline, Avril Halstead, Jason Harris, John Ralyea, and Alexander Tieman, 2019, "Indonesia's Public Wealth: a Balance Sheet Approach to Fiscal Policy Analysis", IMF Working Paper WP/19/81 (Washington: International Monetary Fund).

Eurostat, 2013, European System of Accounts ESA 2010, Publications Office of the European Uniton: Luxembourg, Luxembourg

Finanzministerium. 1933. "Finanzieller Überblick über den Reichshaushaltsplan.” Berlin, Germany

Giammarioli, Nicola, Christiane Nickel, Philipp Rother, and Jean-Pierrer Vidal, 2007, "Assessing Fiscal Soundness Theory and Practice", European Central Bank Occational Paper Series No. 56/March 2007. 
Gamber, Edward, and John Seliski, 2019, "The Effect of Government Debt on Interest Rates”, Congressional Budget Office Working Paper 2019-01.

Gonguet, Fabien, and Klaus-Peter Hellwig, 2019, "Public Wealth in the United States", IMF Working Paper WP/19/139 (Washington: International Monetary Fund).

Gruber, Joseph W., and Steven B. Kamin, "Fiscal Positions and Government Bond Yields in OECD Countries”, Federal Reserve Board International Finance Discusssion Paper N. 1011

Huges, Richard, 2019, "Seeing Public Value: The Case for Balance Sheet Targeting in Fiscal Policy”, Resolution Foundation: London, United Kingdom

International Monetary Fund. 2012. "Fiscal Frameworks for Resource-Rich Developing Countries.” IMF Staff Discussion Note 12/04, Washington, DC.

International Monetary Fund, 2018, "Managing Public Wealth”, October 2018 Fiscal Monitor (Washington: International Monetary Fund).

International Monetary Fund, 2019, Public Sector Balance Sheet Database

Jaramillo, L., C. Mulas-Granados, and E. Kimani. 2017. “Debt Spikes and Stock Flow Adjustments: Emerging Economies in Perspective.” Journal of Economics and Business 94: $1-14$

Kneebone, Ronald D., and Kenneth J. McKenzie, 1999, "The Characteristics of Fiscal Policy in Canada", Canadian Public Policy, 25(4), pp. 483-501

Koshima, Yugo, 2019, “Japan’s Public Sector Balance Sheet”, IMF Working Paper WP/19/212 (Washington: International Monetary Fund).

Krishnamurthy, Arvind and Annette Vissing-Jorgensen, 2012, "The Aggregate Demand for Treasury Debt”, Journal of Political Economy, 120(2), pp. 233-267

Laubach, Thomas, 2003, "New Evidence on the Interest Rate Effects of Budget Deficits and Debt”, Federal Reserve Board Finance and Economics Discussion Series 2003-12.

League of Nations. 1938. “Questionnaire on Public Debt.” Document C.L.51.1938.II.A, Geneva

McCaulay, Martin, 2013, "Duration and Convexity for Pension Liabilities”, Society of Actuaries Pension Section News No. 81.

Matier, Chris, 2012, "Renewing the Canada Health Transfer: Implications for Federal and Provincial-Territorial Fiscal Sustainability", Office of the Parliamentary Budget Officer: Ottawa, Canada.

Munnell, Alicia, Jean-Pierre Aubry, and Laura Quinby, 2011, “The Impact of Pensions on State Borrowing Costs", Center for Retirement Research Issue in Brief, No. 14/2011

New Zealand Treasury, 2018, Ha Puna Hao Patiki 2018 Investment Statement, New Zealand Treasury: Wellington, New Zealand

Office for Budget Responsibility, 2011, Fiscal Sustainability Report 2011, Office for Budget 
Responsibility: London, United Kingdom.

Office for Budget Responsibility, 2018, Fiscal Sustainability Report 2018, Office for Budget Responsibility: London, United Kingdom.

Office for National Statistics, 2019, "National Accounts Articles: Changes to the Capital Stock Estimation Methods for Blue Book 2019”, Office for National Statistics: London, United Kingdom.

Office of Parliamentary Budget Officer, 2017, Fiscal Sustainability Report 2017, Office of Parliamentary Budget Officer: Ottawa, Canada.

Poghoyan, Tigran, 2012, "Long-Run and Short-Run Determinants of Sovereign Bond Yields in Advanced Economices", IMF Working Paper WP/12/271 (Washington: International Monetary Fund).

Reinhart, Vincent and Brian Sack, 2000, “The Economic Consequences of Disappearing Government Debt", Brookings Papers on Economic Activity, 2000(2), pp. 163-220

Rocher, Francois, and Miriam Smith, 2002, “Federalism and Health Care: The Impact of Political-Institutional Dynamics on the Canadian Health Care System", Commission on the Future of Health Care in Canada Discussion Paper No. 18

Seiferling, M., and S. Tareq. 2015. "Fiscal Transparency and the Performance of Government Financial Assets.” IMF Working Paper 15/9, International Monetary Fund, Washington, DC.

Shiller, Ilona, and Ishmael Radikoko, 2014, "Fuzzy Liability Driven Pension Fund Management", Journal of Accounting and Finance, 14(1), pp. 23-50

The Economist, 2020, "The Pandemic will leave the rich world deep in debt, and force some hard choices", The Economist on April 23, 2020

Thorlby, Roth, and Jo Maybin, 2010, A High-Performing NHS? A Review of Progress 19972010, The King's Fund: London, United Kingdom

Traa, B., and A. Carare. 2007. "A Government's Net Worth.” Finance and Development 44 (2): 46-49

Trehan, Bharat, and Carl E. Walsh, 1988, "Common Trends, The Government's Budget Contraint, and Revenue Smoothing", Jounal of Economic Dynamics and Control, 12(2-3), pp.425-444

Trigaux, Damien, Lien Wijnants, Frank De Troyer, and Karen Allacker, "Life Cycle Assessment and Life Cycle Costing of Road Infrastructure in Residential Neighbourhoods", The International Journal of Life Cycle Assessment, 22, pp.938-951

Turner, David, and Francesca Spinelli, 2011, "Explaining the Interest-Rate-Growth Differential Underlying Government Debt Dynamics”, OECD Economis Department Working Paper ECO/WKP(2011)88 
United Nations Population Division, 2017, World Population Prospects 2017, United Nations: New York, New York.

Wilde, W. James, Luke Thompson, and Thomas J. Wood, 2014, “Cost Effective Pavement Preservation Solutions for the Real World", Minesota Department of Transportation: St. Paul, Minesota.

Yousefi, Seyed Reza, 2019, "Public Sector Balance Sheet Strength and the Macro Economy”, IMF Working Paper WP/19/170 (Washington: International Monetary Fund).

Zhang, Zhibo, Samuel Labi, Jon D. Fricker, and Kumares C. Sinha, 2017, Strategic Scheduling of Infrastructure Repair and Maintenance, Volume 2, Purdue University: West Lafayette, Indiana 